\title{
Crack Fault Diagnosis and Location Method for a Dual-disks Hollow Shaft Rotor System Based on the Radial Basis Function Network and Pattern Recognition Neural Network
}

\author{
Yuhong Jin \\ Harbin Institute of Technology \\ Lei Hou ( $\nabla$ houlei@hit.edu.cn ) \\ Harbin Institute of Technology https://orcid.org/0000-0003-0271-7323 \\ Zhenyong Lu \\ Shandong Normal University \\ Yushu Chen \\ Harbin Institute of Technology
}

\section{Original Article}

Keywords: Hollow shaft rotor, Breathing crack, Radial basis function network, Pattern recognition neural network

Posted Date: October 28th, 2020

DOI: https://doi.org/10.21203/rs.3.rs-96920/v1

License: (c) (i) This work is licensed under a Creative Commons Attribution 4.0 International License.

Read Full License 


\section{Title page}

\section{Crack fault diagnosis and location method for a dual-disks hollow shaft rotor system based on the Radial basis function network and Pattern recognition neural network}

Yu-Hong Jin, born in 1998, is currently a master candidate at School of Astronautics, Harbin Institute of Technology, China. His research interests include machine learning and nonlinear dynamics.

E-mail: 20s018042@stu.hit.edu.cn

Lei Hou, born in 1987, is currently an associate professor and a PhD candidate supervisor at School of Astronautics, Harbin Institute of Technology, China. He received his PhD degree from Harbin Institute of Technology, China, in 2015. His main research interests include nonlinear dynamics, rotor dynamics, vibration control, fault diagnosis.

E-mail: houlei@ hit.edu.cn

Zhen-Yong Lu, born in 1988, is currently a lecturer at Institute of Dynamics and Control Science, Shandong Normal University, China. He received his $\mathrm{PhD}$ degree from Harbin Institute of Technology, China, in 2017. His research interests include nonlinear dynamics, rotor dynamics, crack fault diagnosis.

E-mail: luzy@sdnu.edu.cn

Yu-Shu Chen, born in 1931, is currently a professor and a $\mathrm{PhD}$ candidate supervisor at School of Astronautics, Harbin Institute of Technology, China. His main research interests include nonlinear dynamics and its applications in engineering.

E-mail: yschen@ hit.edu.cn

Corresponding author: Lei Hou E-mail: houlei@hit.edu.cn 


\title{
Crack fault diagnosis and location method for a dual-disks hollow shaft rotor system based on the Radial basis function network and Pattern recognition neural network
}

\author{
Yu-Hong Jin ${ }^{1}$ Lei Hou ${ }^{1} \cdot$ Zhen-Yong Lu$^{2} \cdot$ Yu-Shu Chen ${ }^{1}$
}

Received June xx, 201x; revised February xx, 201x; accepted March xx, 201x

(C) Chinese Mechanical Engineering Society and Springer-Verlag Berlin Heidelberg 2017

1 Abstract: In recent years, the crack fault is one of the most27

2 common faults in the rotor system, and its fault diagnosis has 28

3 been paid close attention by researchers. However, the traditional 29

4 fault diagnosis methods based on various signal processing 30

5 algorithms can only be adopted to determine whether there is $a^{31}$

6 crack fault in the rotor system, but the dynamic response of the $\mathrm{e}^{32}$

7 rotor system can hardly be used to calculate the depth and 33

8 position of the crack. In this paper, a new crack fault diagnosis ${ }^{34}$

9 and location method for a dual-disks hollow shaft rotor system 35

10 based on the Radial basis function (RBF) network and Pattern ${ }^{36}$

11 recognition neural network (PRNN) is presented. Firstly, a rotor ${ }^{37}$

12 system model with a breathing crack suitable for a short-thick ${ }^{38}$

13 hollow shaft rotor is established based on the finite element ${ }^{39}$

14 method and Timoshenko beam theory. Then the dynamic 40

15 response is calculated by the harmonic balance method and the $\mathrm{e}^{41}$

16 analysis results show that the first critical whirl speed, the first 42

17 subcritical speed, the first critical speed amplitude, and the ${ }^{43}$

18 super-harmonic resonance peak at $1 / 2$ first critical whirl speed of ${ }^{44}$

19 the rotor system are closely related to the depth and position of 45

20 the crack, which can be used for crack fault diagnosis. Finally, the ${ }^{46}$

21 RBF network and PRNN are adopted to determine the depth and 47

Lei Hou

houlei@hit.edu.cn

1 School of Astronautics, Harbin Institute of Technology, Harbin 150001, P. R. China

2 Institute of Dynamics and Control Science, Shandong Normal University, Ji'nan 250014, P. R. China

\section{Introduction}

Rotating machinery is an important part of the modern industry, which has many applications in gas turbines, aero-engine, wind turbines, and other important machinery equipment. Because the working environment of rotating machinery is harsh, it is easy to generate mechanical failure. The crack fault is one of the most common failure forms in the rotor system, which can pose a serious threat to the reliability of rotating machinery operating. Therefore, timely and accurate fault diagnosis to the crack fault is of great significance to improve the operation reliability of rotating machinery. Since the 1970s, many researchers have studied the crack fault diagnosis of the rotor system in many aspects. Mayes et al. [1] first used a more accurate cosine breathing function to describe the breath behavior of the crack, and studied the dynamic response of the rotor system containing a breathing crack. Then Al-Shudeifat et al. [2][3] proposed a new type of breathing function by using the Fourier series and compared it with Mayes' results. The comparative results show that this respiration function could more accurately represent the breathing process of crack, but its form is more complex. Jun et al. [4] established the equation of motion for a simple rotor with a breathing crack. It is found that the vibration characteristics of a cracked rotor are best identified from the second harmonic components near to the second harmonic resonant speed. Babu et al. [5] used Hilbert-Huang transform (HHT) for transient response of a cracked rotor and the HHT spectrum showed that the sub-harmonics is a typical characteristic of a crack. Chasalevris et al. [6] considered the coupling problem of longitudinal vibration and flexural vibration of the rotor system with two transverse breathing cracks, and the 
1 phenomenon of the natural frequency of the rotor system51

2 change with the increase of the crack depth for transverse52

3 cracks is discovered. Darpe et al. [7] analyzed the53

4 influence of the interaction of the two cracks on the54

5 breathing behavior and the dynamic response of the55

6 Jeffcott rotor based on the concepts of fracture mechanics.56

7 It is found that significant transformations in the dynamic57

8 response of the rotor when the angle between the two crack58

9 directions changes. Xiang et al. [8] considered an59

10 asymmetric rotor-bearing system with coupling faults of60

11 crack and rub-impact under oil-film forces and study the61

12 effects of crack depth on the onset of instability and62

13 nonlinear responses of the rotor-bearing system. Hou et al.63

14 [9][10] found the super-harmonic resonance phenomenon64

15 of the cracked rotor due to maneuver load. Lu et al. [11]65

16 studied the dynamic response of a hollow shaft dual-rotor66

17 system with breathing crack and unbalanced excitation. In67

18 the spectrum, it is found that the peak value of the 68

19 super-harmonic resonance is related to the dimensionless69

20 depth of the crack. Fu et al. [12] gives similar results in the70

21 dynamic response of a normally cracked rotor system with71

22 uncertain crack parameters. Most of these studies focus on72

23 the dynamic response characteristics of the cracked rotor73

24 system or only qualitative analysis of the influence of the74

25 crack parameters (such as the depth and location of the75

26 crack). However, in many cases, crack fault diagnosis76

27 requires quantitative relationships between the dynamic77 and carried out experimental verification. Vashisht et al. [18] investigated the effect of crack on a complex rotor system with ball bearing and advanced a crack detection method using switching control strategy and Short Time Fourier Transform. Pavan et al. [19] used some statistical methods to reduce the fault vibration features, then use the BP neural network and SVM to study the fault diagnosis problem of a dual-disk rotor system. Failure types include a crack in the outer race, inner race with spall and pitting in balls, and comparative test results show that neural network is better than SVM. Bin et al. [20] proposed a new approach for rotating machinery fault diagnosis based on wavelet packet decomposition (WPD)-EMD fault feature extraction and the neural network. Ma et al. [21] presented a diagnosis method for rotor and bearing faults of rotating machinery based on ensemble learning. In this study, the method by weighting and integrating the Convolution Residual Network (CRN), Deep Belief Network (DBN), and Deep AutoEncoder (DAE) obtains great effect on the problem of multi-fault classification. Wang et al. [22] determined the crack parameters including crack location, depth, and angle for a solid shaft by using Kriging Surrogate Model and improved nondominated sorting genetic algorithm-III (NSGA-III), which has high parameter identification accuracy. Zhang et al. [23] studied the application of the fuzzy neural network to the fault diagnosis system for rotary machines and experimental results verified that fuzzy neural network has good identification ability. Wang et al. [24] used K-means clustering method to classify crack fault for a planetary gear box. Li et al. [25] studied multiple crack identification based on the three steps meshing, and experimental verification was also carried out. Most researchers' objects are relatively simple Jeffcott rotors or solid shaft rotors, nevertheless, to improve the rotor operating efficiency in practical problems, most large complex rotor systems adopt the hollow shaft. At present, there are relatively little researches on crack fault diagnosis of hollow shaft rotor systems.

In this study, a new crack fault diagnosis and location method for a two-disk hollow shaft rotor system is proposed by using the RBF neural network and pattern recognition network. At present, the research object of most researchers about the rotor system crack fault diagnosis is the relatively simple solid shaft rotor or Jeffcott rotor and there are little researches on the hollow shaft rotor. Besides, many researchers focus on the pattern recognition of the crack fault in the various faults of the rotor system or calculating the crack depth with fixing the crack position. In practice, to improve the operating 
1 efficiency of the rotor system, the shaft is often designed to 46

2 be hollow and the actual crack failure may occur at any

3 position of the shaft, it is a challenge to identify the crack

4 parameters when the depth and location of the crack are

5 both unknown. In this paper, the dynamic response of a

6 cracked dual-disks hollow shaft rotor is studied, and the

$7 \mathrm{RBF}$ network and pattern recognition network are used to

8 solve the crack fault diagnosis problem when the depth and

9 location of the crack are both uncertain, which can better

10 meet the requirements of actual rotor system crack fault

11 diagnosis.

12 The paper is organized as follows, in Section 2, the

13 motion equations of the dual-disk hollow shaft rotor

14 system with a breathing crack are constructed by the finite

15 element method. Secondly in Section 3, the harmonic

16 balance method (HBM) is used to solve the dynamic 47

17 response of the rotor system, and the effect of crack depth 48

18 and position is analyzed respectively, then the 4th order 49

19 Runge-Kutta method is used to verify the results of HBM.50

20 Estimation of crack depth is discussed detailedly based on51

21 RBF neural network and the problem of crack orientation 52

22 is solved by using the pattern recognition network in 53

23 Section 4. Finally, in Section 6, the primary results in this54

24 paper are summarized.
Table 1 The physical parameters of the rotor system

\begin{tabular}{lc}
\hline \multicolumn{1}{c}{ Parameters } & Value (units) \\
\hline Shaft length $(L)$ & $0.8562 \mathrm{~m}$ \\
External radius $(R)$ & $0.0441 \mathrm{~m}$ \\
Inside radius $(r)$ & $0.0110 \mathrm{~m}$ \\
Material density $(\rho)$ & $7800 \mathrm{~kg} / \mathrm{m}^{3}$ \\
Young's modulus $(E)$ & $2.09 \mathrm{Gpa}$ \\
Shear modulus $(G)$ & $80.38 \mathrm{Gpa}$ \\
Bearing stiffness $(K)$ & $5 \times 10^{7} \mathrm{~N} / \mathrm{m}$ \\
Disk 1 diameter $\left(d_{1}\right)$ & $0.1215 \mathrm{~m}$ \\
Disk 1 mass $\left(m_{1}\right)$ & $6.5157 \mathrm{~kg}$ \\
Disk 2 diameter $\left(d_{2}\right)$ & $0.1493 \mathrm{~m}$ \\
Disk 1 mass $\left(m_{2}\right)$ & $3.9543 \mathrm{~kg}$ \\
Amount of unbalance $\left(m_{e} d\right)$ & $5 \times 10^{-7} \mathrm{~kg} \cdot \mathrm{m}$ \\
Unbalance deflection $(\theta)$ & 0 \\
Bearing damping $\left(c_{x x}\right)$ & $1000 \mathrm{Ns} / \mathrm{m}$ \\
\hline
\end{tabular}

\subsection{Crack model}

The crack in the hollow shaft is more complex than that in the solid shaft. Figure 2 shows different crack conditions at disparate crack depth, the dashed area represents the uncracked segment, when the crack is relatively shallow, it is a non-penetrating crack (Figure 2(a)) and when the crack depth is large, it is a passthrough crack (Figure 1(b)). $A_{1}$ and $A_{C}$ represent the cross-sectional area of uncracked and cracked segments respectively. $O-x y$ is the fixed coordinate system and $C-\overline{x y}$ is the centroid coordinate system, where $C$ is the centroid of the section $A_{1}, \Omega, h$ and $e$ represent rotor speed, crack depth, and centroid offset distance. $\alpha$ and $\alpha_{1}$ is the angle between the crack edge and $O$.

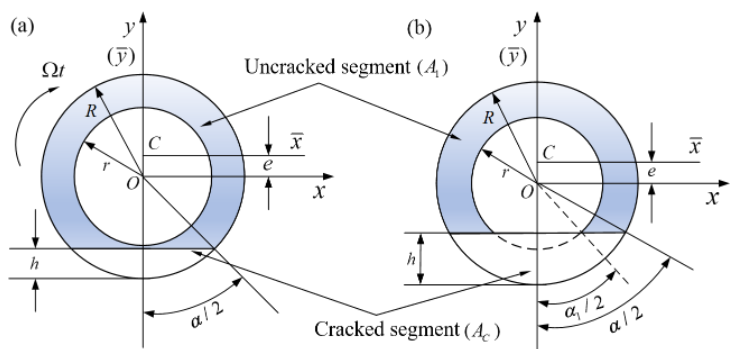

Figure 2 Cross-section diagram of hollow shaft crack: (a) Non-penetrating crack. (b) Passthrough crack. The dashed area represents the uncracked segment

From Figure 2, the moment of inertia of the non-penetrating crack across the $x$ and $y$-axis can be obtained as follows

$$
A_{1}=R^{2}\left(\pi-\cos ^{-1}(1-\lambda)+(1-\lambda) \gamma\right)-\pi r^{2},
$$

$I_{x}^{C}=\frac{\pi R^{2}}{8}-\frac{R^{4}}{4}\left((1-\lambda)\left(2 \lambda^{2}-4 \lambda+1\right) \gamma+\sin ^{-1}(1-\lambda)\right)$, 


$$
\begin{gathered}
I_{y}^{C}=\frac{R^{4}}{12}\left((1-\lambda)\left(2 \lambda^{2}-4 \lambda-3\right) \gamma+3 \sin ^{-1} \gamma\right), \\
e=\frac{2 R^{3}}{3 A_{1}} \gamma^{3},
\end{gathered}
$$

(2b) where $\lambda=h / R$ represent the dimensionless crack depth ${ }^{34}$ and $\gamma=\sqrt{\lambda(2-\lambda)} \cdot \mathrm{I}_{\mathrm{x}}^{\mathrm{C}}$ and $\mathrm{I}_{\mathrm{y}}^{\mathrm{C}}$ is the moment of inertia of ${ }^{35}$ cracked segment $\mathrm{A}_{\mathrm{C}}$ across the $x$ and $y$-axis.

When the crack is deep, the above equation can be37 rewritten as

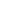

$$
A_{1}=R^{2}\left(\pi-\cos ^{-1}(1-\lambda)+(1-\lambda) \gamma\right)
$$$$
-\left(\pi r^{2}-\alpha_{1} r^{2} / 2+(R-h) \sqrt{r^{2}-(R-h)^{2}}\right)
$$

$$
I_{x}^{C}=R^{2}\left(\pi-\cos ^{-1}(1-\lambda)\left(2 \lambda^{2}-4 \lambda+1\right) \gamma\right.
$$$$
\left.+\sin ^{-1}(1-\lambda)\right)-\int_{-r}^{h-R} 2 x^{2} \sqrt{r^{2}-x^{2}} d x
$$

$$
I_{y}^{C}=\frac{R^{4}}{12}\left((1-\lambda)\left(2 \lambda^{2}-4 \lambda-3\right) \gamma+3 \sin ^{-1} \gamma\right)
$$$$
-\int_{-\sqrt{r^{2}-(R-h)^{2}}}^{0} 2 x^{2}\left(\sqrt{r^{2}-x^{2}}+h-R\right) d x
$$

45

Suppose that $R=1$ and $r=0.5$, Figure 3 shows the curve ${ }^{52}$ of $I_{x}^{C}$ and $I_{y}^{C}$ when $\lambda$ changes from 0 to 1 . It can be seen53 that both $I_{x}^{C}$ and $I_{y}^{C}$ increase with the increase of $\lambda$, but the change trends are different. Furthermore, note that $\mathrm{I}_{\mathrm{x}_{55}}^{54}$ and $I_{y}^{C}$ are the same value at dimensionless depth of the 55 crack $\lambda=1$, this is because the cross section of the crack $^{56}$ element is a semicircle in this case which has the equal ${ }_{58}^{57}$ moment of inertia across the $x$ and $y$-axis. Similar results 58 are also discussed in Refs. [2][3] and [11].

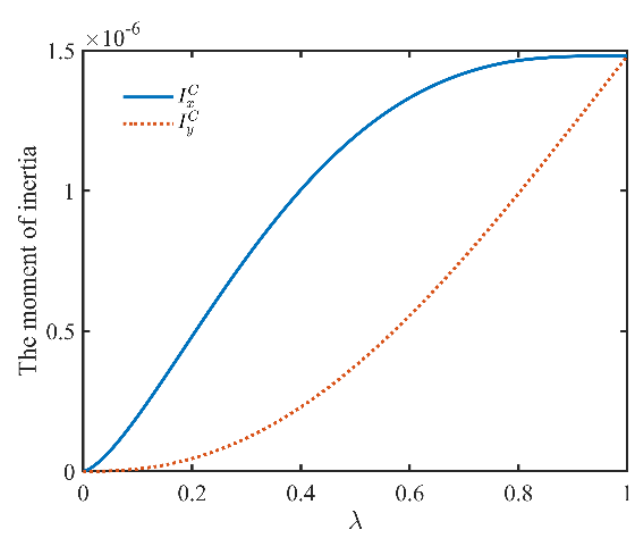

Figure 3 The curve of $\mathrm{I}_{\mathrm{x}}^{\mathrm{C}}$ and $\mathrm{I}_{\mathrm{y}}^{\mathrm{C}}$ with respect to $\lambda(R=1$, $r=0.5$ )

The moment of inertia of the uncracked intact shaft ${ }_{68}^{67}$ section relative to $x$ and $y$ axes is noted as $I$, then according 68 to the principle of superposition of the moment of inertia, the inertia moment of uncracked segment $A_{1}$ can be given as

$$
\begin{aligned}
& I_{1}=I-I_{x}^{C}, \\
& I_{2}=I-I_{y}^{C},
\end{aligned}
$$

where $I=\pi\left(R^{4}-r^{4}\right) / 4$, subsequently, the area moment of inertia of cross-section $A_{1}$ relative to the fixed coordinate system $O-x y$ need to convert to the centroid coordinate system $C$ - $\overline{x y}$, which can be denoted as $\overline{I_{1}}$ and $\overline{I_{2}}$ respectively and obtained by the parallel axis shift theorem as follows

$$
\begin{gathered}
\bar{I}_{1}=I_{1}-A_{1} e^{2}, \\
\bar{I}_{2}=I_{2},
\end{gathered}
$$

During the rotation of the rotor, the crack will periodically open and close due to the influence of the rotor's weight so it is necessary to introduce a breathing function to approximate this process. In this paper, the cosine breathing function proposed by Mayes[1] is adopted, which is given as

$$
f(t)=\frac{1}{2}(1+\cos (\Omega t))
$$

where $\Omega$ is the rotational speed of the shaft. Then the time-varying moment of inertia of the crack element can be calculated as.

$$
\begin{gathered}
I_{\bar{x}}(t)=I-\left(I-\bar{I}_{1}\right) f(t)=I-\left(I_{x}^{C}+A_{1} e^{2}\right) f(t), \\
I_{\bar{y}}(t)=I-\left(I-\bar{I}_{2}\right) f(t)=I-I_{y}^{C} f(t),
\end{gathered}
$$

When a crack appears at element $j$, the time-varying stiffness matrix of the crack element is calculated as follows.

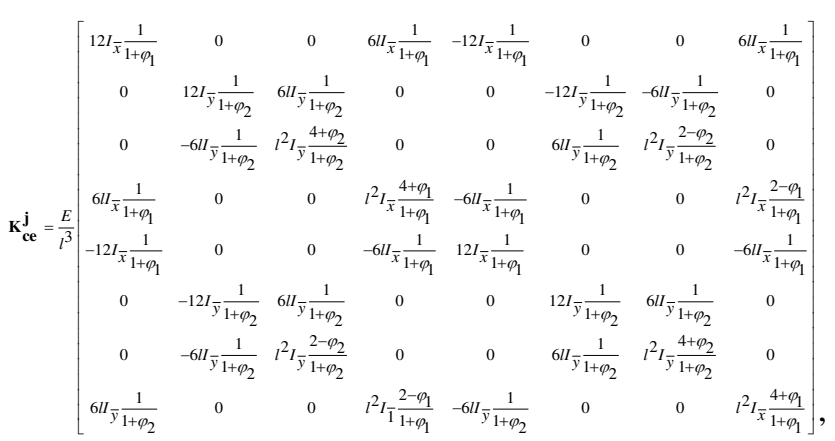


1 where $\varphi_{1}=\frac{12 E I_{\bar{x}}}{\mu A_{c e} G l^{2}}$ and $\varphi_{2}=\frac{12 E I_{\bar{y}}}{\mu A_{c e} G l^{2}}, \mu$ is Poisson47

2 ratio of the material, $l$ is element length.

For simplicity, formula (11) can also be given in the 50 following form

$$
\mathbf{K}_{\mathbf{c e}}^{\mathbf{j}}=\mathbf{K}^{\mathbf{j}}-f(t) \mathbf{K}_{\mathbf{c}}^{\mathbf{j}}=\left(\mathbf{K}^{\mathbf{j}}-\frac{1}{2} \mathbf{K}_{\mathbf{c}}^{\mathbf{j}}\right)-\frac{1}{2} \cos (\Omega t) \mathbf{K}_{\mathbf{c}}^{\mathbf{j}},
$$

where $\mathbf{K}^{\mathbf{j}}$ is the stiffness matrix of the intact shaft element, $\mathbf{K}_{\mathbf{c}}^{\mathbf{j}}$ is the reduced stiffness matrix representing 53 the effect of crack, which can be obtained by replacing the $I_{\bar{x}}$ and $I_{\bar{y}}$ in Equation (11) with and respectively.

\subsection{The motion equation of the rotor system}

According to rotor dynamics finite element method, ${ }_{55}$ Timoshenko beam theory and Lagrange equation, the 56 motion equation of a dual-disk hollow shaft rotor with $\mathrm{a}_{57}$ breathing crack can be given as follow

(n)

$$
\begin{aligned}
& \mathbf{M q}(t)+\operatorname{exq}(t)+\left(\mathbf{R}^{2}-\frac{1}{2} \mathbf{K}_{\mathbf{c}} \cos \Omega t\right) \mathbf{q}(t)= \\
& \mathbf{F}_{1} \cos \Omega t+\mathbf{F}_{2} \sin \Omega t+\mathbf{F}_{\mathbf{g}}
\end{aligned}
$$

where $\mathbf{R}^{8}=\mathbf{K}-1 / 2 \mathbf{K}_{\mathbf{c}}, \mathbf{C}=\mathbf{C}+\mathbf{G} . \mathbf{M}, \mathbf{C}, \mathbf{G}$ and $\mathbf{K}_{63}^{62}$ represent the global mass matrix, damping matrix, rotation 64 matrix and stiffness matrix of the intact rotor system $_{65}$ including flexible shaft element, disk, bearing and support, 66 all of which are $4(N+1) \times 4(N+1)$ matrix, $N$ is the 67 number of elements. $\mathbf{K}_{\mathbf{c}}$ is the reduced stiffness matrix of 68 the crack element, which is $\mathbf{K}_{\mathbf{c}}^{\mathbf{j}}$ in the element $j \operatorname{and}_{69}$ others are 0. $\mathbf{q}(t)$ is $4(N+1)$ the displacement vector of 70 nodes, each node has 2 lateral displacements and 2 bending 71 angles. $\mathbf{F}_{1}$ and $\mathbf{F}_{2}$ is the component of the unbalanced ${ }_{72}$ excitation in $x$ and $y$ direction, $\mathbf{F}_{\mathrm{g}}$ is equivalent gravity ${ }_{73}$ force on the node and all of them are $4(N+1)$ vector. The 74 specific forms of each matrix and vector in formula 13 are $_{75}$ shown in the appendix.

\section{Dynamic response analysis}

\subsection{Equation solving}

In this paper, the Harmonic Balance Method (HBM) is 81 used to solve equation (13). HBM supposes that the stable ${ }_{83}^{82}$ solution of the equation has the finite Fourier series 8 solution

$$
\mathbf{q}(t)=\mathbf{A}_{\mathbf{0}}+\sum_{j=1}^{n}\left(\mathbf{A}_{\mathbf{j}} \cos (k \Omega t)+\mathbf{B}_{\mathbf{j}} \cos (k \Omega t)\right)
$$

where $n$ is the number of harmonics used in HBM and it can be determined according to the accuracy requirement. This paper takes $n=4$ and inserts solution (14) in equation (13) yields

$$
\left[\begin{array}{cccccccc}
\hat{\mathbf{K}} & \mathbf{P}_{11} & \mathbf{P}_{21} & \mathbf{0} & \mathbf{0} & \mathbf{0} & \mathbf{0} & \mathbf{0} \\
-\mathbf{P}_{11} & \mathbf{P}_{31} & \mathbf{0} & \mathbf{P}_{21} & \mathbf{0} & \mathbf{0} & \mathbf{0} & \mathbf{0} \\
\mathbf{P}_{22} & \mathbf{0} & \mathbf{P}_{32} & \mathbf{P}_{12} & \mathbf{P}_{22} & \mathbf{0} & \mathbf{0} & \mathbf{0} \\
\mathbf{0} & \mathbf{P}_{22} & -\mathbf{P}_{12} & \mathbf{P}_{32} & \mathbf{0} & \mathbf{P}_{22} & \mathbf{0} & \mathbf{0} \\
\mathbf{0} & \mathbf{0} & \mathbf{P}_{23} & \mathbf{0} & \mathbf{P}_{33} & \mathbf{P}_{13} & \mathbf{P}_{23} & \mathbf{0} \\
\mathbf{0} & \mathbf{0} & \mathbf{0} & \mathbf{P}_{23} & -\mathbf{P}_{13} & \mathbf{P}_{33} & \mathbf{0} & \mathbf{P}_{23} \\
\mathbf{0} & \mathbf{0} & \mathbf{0} & \mathbf{0} & \mathbf{P}_{24} & \mathbf{0} & \mathbf{P}_{34} & \mathbf{P}_{14} \\
\mathbf{0} & \mathbf{0} & \mathbf{0} & \mathbf{0} & \mathbf{0} & \mathbf{P}_{24} & -\mathbf{P}_{14} & \mathbf{P}_{34}
\end{array}\right]\left[\begin{array}{c}
\mathbf{A}_{1} \\
\mathbf{B}_{1} \\
\mathbf{A}_{2} \\
\mathbf{B}_{2} \\
\mathbf{A}_{3} \\
\mathbf{B}_{3} \\
\mathbf{A}_{4} \\
\mathbf{B}_{4}
\end{array}\right]=\left[\begin{array}{c}
\mathbf{F}_{1} \\
\mathbf{F}_{2} \\
\mathbf{0} \\
\mathbf{0} \\
\mathbf{0} \\
\mathbf{0} \\
\mathbf{0} \\
\mathbf{0}
\end{array}\right],
$$

where $\mathbf{K}^{\mathbf{t}}=\mathbf{R}^{\mathbb{R}^{\circ}}-\Omega^{2} \mathbf{M}-1 / 8 \mathbf{K}_{\mathrm{c}} \mathbf{R}^{-1} \mathbf{K}_{\mathrm{c}}, \mathbf{P}_{1 \mathrm{i}}=i \Omega \mathfrak{c}, \quad \mathbf{P}_{2 \mathrm{i}}=$ $1 / 4 \mathbf{K}_{\mathbf{c}}, \quad \mathbf{P}_{3 \mathbf{i}}=\mathbf{R}^{\circ}-(i \Omega)^{2} \mathbf{M}, \quad \mathbf{F}_{1}^{o}=\mathbf{F}_{\mathbf{1}}-1 / 2 \mathbf{K}_{\mathbf{c}} \mathbf{R}^{\sigma^{-1}} \mathbf{F}_{\mathbf{g}}$, $i=1,2,3,4$. After solving the linear equations of equation (15) to obtain the coefficients of each harmonic component, the direct component Ao can be calculated as follow

$$
\mathbf{A}_{0}=\mathbf{R}^{\sigma^{-1}}\left(\mathbf{F}_{\mathrm{g}}-\frac{1}{4} \mathbf{K}_{\mathbf{c}} \mathbf{A}_{1}\right)
$$

The dynamic response of the cracked rotor can be obtained by equation (14), equation (15), and equation (16). When there is no crack fault in the double-disk rotor system, the first 4 order critical speeds are $\omega_{1}=825.1 \mathrm{rad} / \mathrm{s}$, $\omega_{2}=1359.2 \mathrm{rad} / \mathrm{s}, \omega_{3}=1415.6 \mathrm{rad} / \mathrm{s}$, and $\omega_{4}=2183.0 \mathrm{rad} / \mathrm{s}$ according to the physical parameters in Table 1 .

\subsection{Effects of dimensionless crack depth}

The position of the crack $c_{p}$ is fixed at element 10 and Error! Reference source not found. shows the $3 \mathrm{D}$ waterfall diagram of rotor speed-dimensionless crack depth-amplitude at node 10 under the low speed (near the first critical speed $\omega_{1}$ ) at the different crack depth of the rotor system. Node amplitude is calculated as

$$
a_{i}=\sqrt{u_{i}^{2}+v_{i}^{2}}
$$

where $a_{i}$ is the amplitude of node $i, u_{i}$ is the horizontal displacement of node $i$, and $v_{i}$ is the vertical displacement of node $i$. Analysis from Figure 4 shows that the rotor system has obvious resonance peaks near the first critical speed, besides, compared to the intact rotor system without crack, the cracked rotor system 
1 will have super-harmonic resonances near $1 / 2,1 / 3$, or33

2 even 1/4 first-order critical speed due to the occurrence34

3 of crack, when the crack depth is relatively shallow, the 35

4 rotor system will firstly appear obvious super-harmonic36

5 resonance peaks at $1 / 2 \omega_{1}$ and $1 / 3 \omega_{1}$, and as the crack37

6 depth gradually increases, there will be super-harmonic38

7 resonance peaks at $1 / 4 \omega_{1}$, but compared to the peaks at 39

$81 / 2 \omega_{1}$ and $1 / 3 \omega_{1}$, the subcritical resonance peak at $1 / 440$

$9 \omega_{1}$ is weak. Furthermore, with the dimensionless crack 41

10 depth improves, the super-harmonic resonance peaks 42

11 near $1 / \mathrm{n} \omega_{1} \quad(\mathrm{n}=2,3,4)$ tend to be obvious, which 43

12 indicates that the peak value of super-harmonic44

13 resonances near $1 / \mathrm{n}(\mathrm{n}=2,3,4)$ first-order critical speed 45

14 is closely related to the dimensionless depth of the crack 46

15 Moreover, Figure 5 shows the amplitude-frequency 47

16 response curves at node 11 with $\lambda=0,0.3,0.6,0.9$, and 48

$17 c_{p}=10$. It can be observed that crack slightly reduces 49

18 the first-order critical speed of the rotor system, and50

19 with the increase of crack depth, the super-harmonic51

20 resonance peaks become more and more obvious.

value of super-harmonic resonance are closely related to the dimensionless crack depth. These dynamic characteristics can be used as the basis for fault diagnosis of the depth of the crack.

\subsection{Influence of crack position}

The dimensionless crack depth $\lambda$ is fixed at 0.5 and Error! Reference source not found. shows the $3 D$ waterfall diagram of rotor speed-crack position-amplitude at node 10 under the low speed (near the first critical speed $\omega_{1}$ ) at the different crack position of the rotor system. From Error! Reference source not found. it can be seen that when the crack is located at both ends of the rotor system, the effect on the dynamic response of the rotating system is weak, the peak value of super-harmonic resonance in amplitude-frequency response is unobvious. However, when the crack gradually approaches the middle of the rotor system, the super-harmonic resonance peak will increase. When the crack is located in the middle of the rotor system, the super-harmonic resonance of the rotor system is most obvious. At this time, the crack has the greatest impact on the dynamic response of the rotor system and it indicates that the peak value of super-harmonic resonance near $1 / n(n=2,3,4)$ first critical speed of the rotor system is related to the crack position.

The crack position also has a certain influence on the critical speed of the rotor system. Error! Reference source not found. shows the amplitude-frequency response curves at node 10 near the main resonance area when the crack is located at element $1,3,5$, and 10 , where the corresponding first critical speed is $824.3 \mathrm{rad} / \mathrm{s}$ $822.1 \mathrm{rad} / \mathrm{s}, 819 \mathrm{rad} / \mathrm{s}$, and $814.6 \mathrm{rad} / \mathrm{s}$ separately. It can be found that as the position of the crack moves to the middle of the rotor system, the critical speed of the rotor system will slightly decrease. When the crack is located in the middle of the rotor system, the critical speed of the rotor system is the lowest.

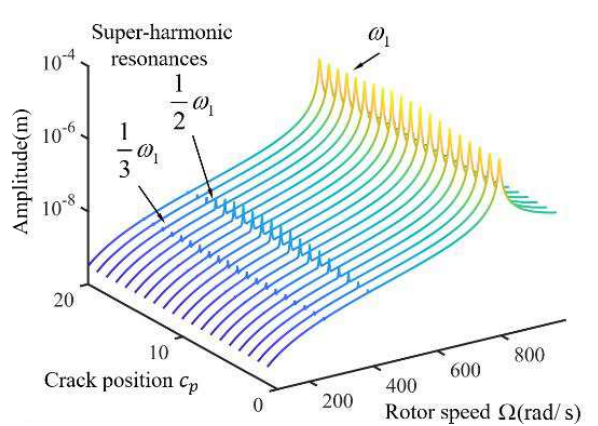

Overall, the generation of crack can lead to the
henomenon of super-harmonic resonance near $1 / \mathrm{n} \omega_{1}$
$(\mathrm{n}=2,3,4)$, and the first critical speed and the peak

Overall, the generation of crack can lead to the
phenomenon of super-harmonic resonance near $1 / n \omega_{1}$
$(n=2,3,4)$, and the first critical speed and the peak

Overall, the generation of crack can lead to the
phenomenon of super-harmonic resonance near $1 / n \omega_{1}$
$(n=2,3,4)$, and the first critical speed and the peak

Figure 5 Amplitude-frequency response curves for different crack depth at node $10\left(c_{p}=10\right)$ 
1 Figure 6 3D waterfall diagram of rotor speed-crack16

2 position-amplitude at node $10(\lambda=0.5)$

4 Figure 7 Amplitude-frequency response curves for different 28

5 crack position at node $10(\lambda=0.5)$

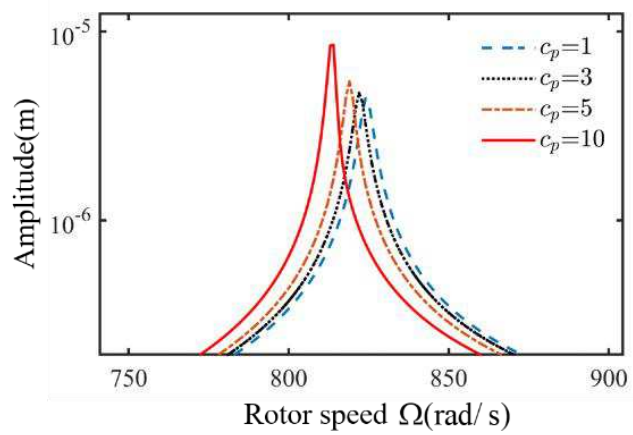

17

In short, the crack position affects the dynamic response of the rotor system. When the depth of the crack is constant 32 the closer the crack is to the middle of the rotor system, the 33 more obvious the main resonance peak value and the ${ }_{34}$ super-harmonic resonance peak at $1 / \mathrm{n}$ critical speed are $_{35}$ and the smaller the critical speed is. These conclusions 36 have been confirmed in Refs. [26], which can be used as 37 the theoretical basis for identifying crack position.

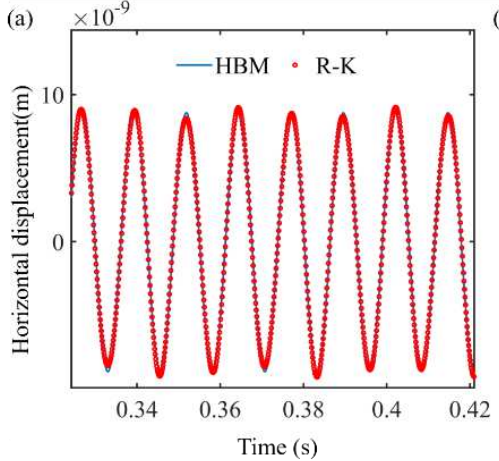
Time history. (b) Whirling orbits. (c) Frequency spectrum.

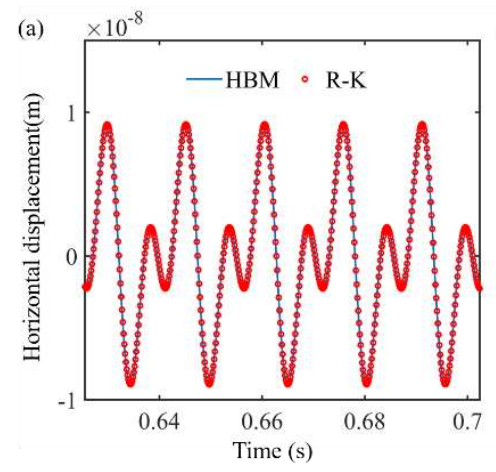
node 10: (a) Time history. (b) Whirling orbits. (c) Frequency spectrum.

\subsection{Numerical verification}

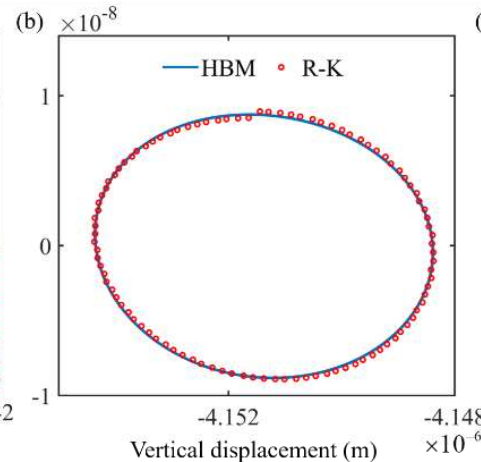

To verify the accuracy of the HBM adopted in this paper, this section uses the fourth-order Runge-Kutta method (R-K) to solve equation (13) and compares the results of HBM. Figure 8 shows time history, whirling orbits, and frequency spectrum solved by HBM and R-K respectively for $\lambda=0.3, c_{p}=10$ and $\Omega=500 \mathrm{rad} / \mathrm{s}$, it can be seen that the calculation results are similar. At this time, the whirling orbit of the rotor system is an ellipse, and there is no multiple frequency components in the frequency spectrum, which indicates that there is no super-harmonic resonance phenomenon in the rotor system.

Moreover, Figure 9 shows time history, whirling orbits, and frequency spectrum solved by HBM and R-K respectively for $\lambda=0.3, c_{p}=10$ and $\Omega=410 \mathrm{rad} / \mathrm{s} \approx$ $1 / 2 \omega_{1}$ and the 2 nd super-harmonic resonance occurs in this operating speed. It can be seen from Figure 9 that in the case of super-harmonic resonance, the calculation results of $\mathrm{HBM}$ and the $\mathrm{R}-\mathrm{K}$ are still close, and the whirling orbits of the rotor system present shape with two closed loops. At the same time, the $2 \times$ frequency component can be observed in the spectrum. These results are consistent with Refs. [11].

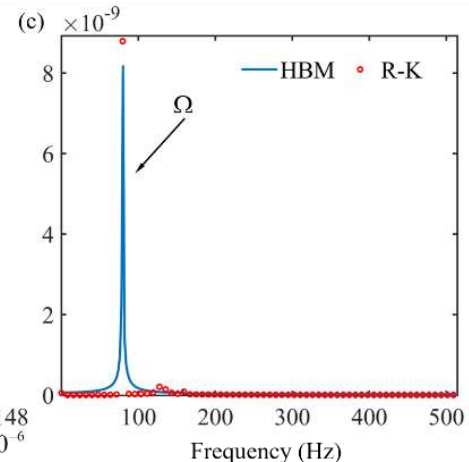

Figure 8 Comparison of time history, whirling orbits, and frequency spectrum for $\lambda=0.3, c_{p}=10$ and $\Omega=500 \mathrm{rad} / \mathrm{s}$ at node 10 : (a)
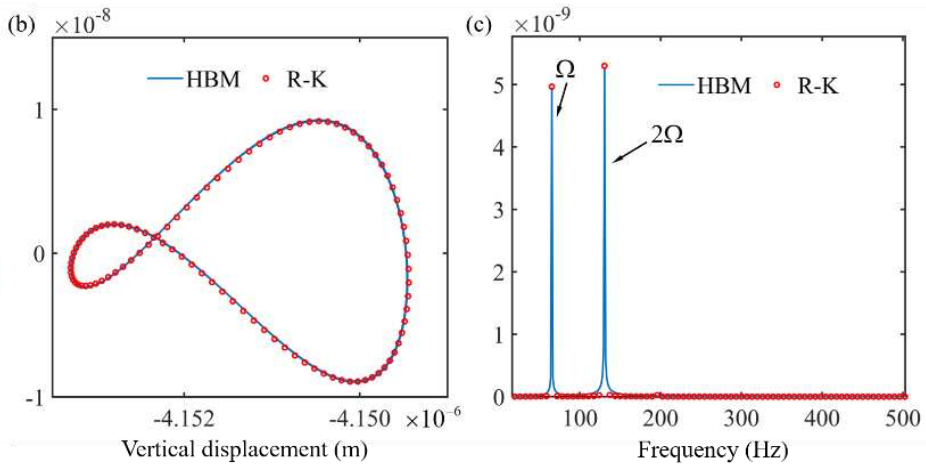

Figure 8 Comparison of time history, whirling orbits, and frequency spectrum for $\lambda=0.3, c_{p}=10$ and $\Omega=410 \mathrm{rad} / \mathrm{s} \approx 1 / 2 \omega_{1}$ at 


\section{The fault diagnosis method of rotor system 31} crack based on neural network

\subsection{Radial basis function neural network}

Radial Basis Function (RBF) neural network is a35 feedforward fully connected neural network. Compared 36 with the traditional Backgroud Propagation (BP) neural37 network, the RBF network generally contains only one38 hidden layer, then uses the radial basis function as the39 activation function in the hidden layer and adopts a direct40 connection between the input layer and hidden layer41 instead of weight connection, as shown in Figure 10.

(a) Input layer Hidden layer 1 Hidden layer 2

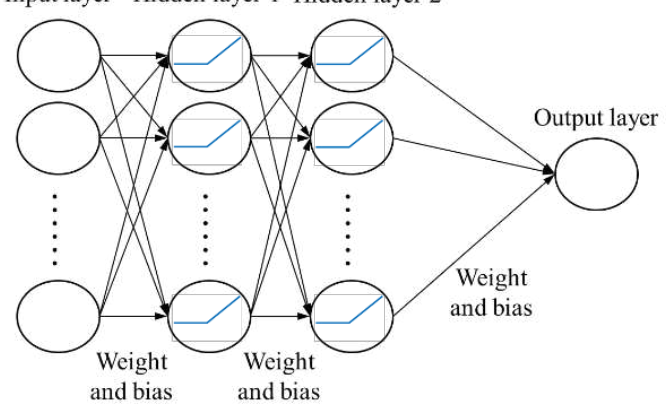

(b)

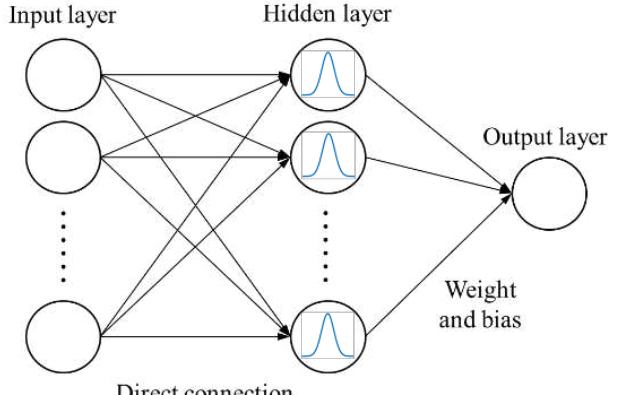

Direct connection
34

the RBF network, and the most commonly used is the Gaussian function, which is given as

\section{const} 42,

Figure 10 Structure of RBF and BP neural network: (a) $\mathrm{RBF}^{55}$ neural network. (b) BP neural network.

The output of the RBF network can be calculated as

$$
y_{i}=\sum_{j=1}^{q} W_{i j} \rho\left(\mathbf{x}, \mathbf{c}_{\mathbf{j}}\right)+b_{i}
$$

where $\mathbf{x}$ is the input vector of RBF network, $\rho\left(\mathbf{x}, \mathbf{c}_{\mathbf{j}}\right)$ is the ${ }^{63}$ activation function of $j$ th hidden layer neuron, $\mathbf{c}_{\mathbf{j}}$ is the 65 center of radial basis function in $j$ th hidden layer neuron, 66 $W_{i j}$ represents the weight between the $j$ th hidden layer neuron and the $i$ th output layer neuron, and $b_{i}$ is the bias of 67 $i$ th output layer neuron, $q$ is the number of hidden layer neuron and $y_{i}$ is the output value of $i$ th output layer neuron. There are various forms of radial basis functions in

\section{t}

\section{basis}

$$
\rho(\mathbf{x}, \mathbf{c})=\exp \left(-\frac{\|\mathbf{x}-\mathbf{c}\|_{2}^{2}}{2 \sigma^{2}}\right),
$$

where $\|\mathbf{x}-\mathbf{c}\|_{2}$ represents the Euclidean norm, which is used to characterize the distance between the input vector and the center of the radial basis function. $\sigma$ is the spread constant of the RBF and it affects the size of the radial basis function activation region. When the input dimension is 2 , take the spread constant is 1 and the center is $(0,0)$, then the Gaussian function image is shown in Figure 11. It can be seen from Figure 11 that the Gaussian function has a relatively sensitive response near the center, while the function value in most areas far away from the center is almost 0 , which means inactive. The nature of local activation allows the RBF network to set up more neurons without overfitting.

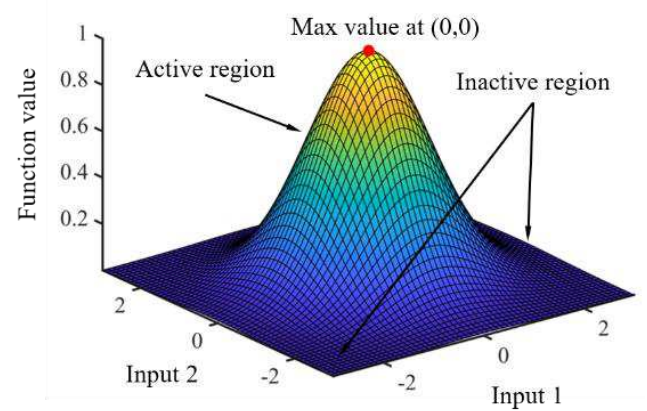

Figure 11 Amplitude-frequency response curves for different crack position at node $10(\lambda=0.5)$

\subsection{Calculate the dimensionless crack depth with RBF network}

The dimensionless depth and position of the crack are assigned by random numbers and then the dynamic response of the crack rotor system can be obtained by using the method in Section 3. The dynamic characteristics of first critical whirl speed, first subcritical speed, first critical speed amplitude, and the super-harmonic resonance peak at $1 / 2$ first critical whirl speed are taken as the input of the RBF network and the output of the RBF network is dimensionless crack depth. Take $70 \%$ of the 188 sets of data as the training set, $15 \%$ as the validation set, and $15 \%$ as the testing set. Some data sets are shown in Table 2 and Table 3. 
Table 2 Part of the data used to train the RBF network

\begin{tabular}{cccccc}
\hline$\lambda$ & $c_{p}$ & $\begin{array}{c}\text { first critical } \\
\text { speed (rad/s) }\end{array}$ & $\begin{array}{c}\text { first critical speed } \\
\text { amplitude }(\log )\end{array}$ & $\begin{array}{c}\text { first critical } \\
\text { speed (rad/s) }\end{array}$ & $\begin{array}{c}\text { first critical speed } \\
\text { amplitude (log) }\end{array}$ \\
\hline 0.4050 & 4 & 822 & -5.4783 & 411 & -8.0111 \\
0.3086 & 10 & 820 & -5.4808 & 410 & -8.0141 \\
0.3149 & 19 & 824 & -5.5058 & 412 & -8.1428 \\
0.3384 & 20 & 825 & -5.5032 & 412 & -8.0971 \\
0.3507 & 13 & 820 & -5.5021 & 410 & -7.9737 \\
0.3919 & 11 & 817 & -5.4271 & 409 & -7.9061 \\
0.4295 & 1 & 824 & -5.4968 & 412 & -7.9544 \\
0.4328 & 3 & 823 & -5.4879 & 411 & -7.9721 \\
0.4749 & 6 & 818 & -5.3933 & 409 & -7.8852 \\
0.4947 & 17 & 821 & -5.4587 & 411 & -7.9143 \\
\hline
\end{tabular}

Table 3 Part of the data used to validate and test the RBF network

\begin{tabular}{cccccc}
\hline$\lambda$ & $c_{p}$ & $\begin{array}{c}\text { first critical } \\
\text { speed (rad/s) }\end{array}$ & $\begin{array}{c}\text { first critical speed } \\
\text { amplitude }(\log )\end{array}$ & $\begin{array}{c}\text { first critical } \\
\text { speed (rad/s) }\end{array}$ & $\begin{array}{c}\text { first critical speed } \\
\text { amplitude }(\log )\end{array}$ \\
\hline 0.5740 & 4 & 820 & -5.4097 & 410 & -7.8359 \\
0.3204 & 6 & 821 & -5.4837 & 411 & -8.0734 \\
0.3889 & 15 & 820 & -5.4652 & 410 & -7.9463 \\
0.5191 & 10 & 813 & -5.0707 & 406 & -7.7704 \\
0.32279 & 5 & 822 & -5.4847 & 411 & -8.0861 \\
0.3319 & 8 & 820 & -5.4774 & 410 & -8.0090 \\
0.3450 & 14 & 820 & -5.4742 & 410 & -7.9882 \\
0.3488 & 3 & 823 & -5.4874 & 412 & -8.0571 \\
0.3512 & 5 & 822 & -5.4925 & 411 & -8.0536 \\
0.3536 & 9 & 819 & -5.4659 & 409 & -7.9957 \\
\hline
\end{tabular}

5 The mean square error (MSE) function is used as the27

6 loss function during the training, which is given as 7

8

$$
M S E=\frac{1}{m} \sum_{k=1}^{m} \sum_{j=1}^{l}\left(\hat{y}_{j}^{k}-y_{j}^{k}\right)^{2},
$$

Table 4 Training parameters of the RBF network

\begin{tabular}{cccccc}
\hline $\begin{array}{c}\text { Loss } \\
\text { function }\end{array}$ & $\begin{array}{c}\text { Max } \\
\text { epochs }\end{array}$ & $\begin{array}{c}\text { Spread } \\
\text { constant }\end{array}$ & $\begin{array}{c}\text { Steps of } \\
\text { validation } \\
\text { failure }\end{array}$ & $\begin{array}{c}\text { Clustering } \\
\text { algorithm }\end{array}$ & $\begin{array}{c}\text { Training } \\
\text { algorithm }\end{array}$ \\
\hline MSE & 100 & 0.8 & 6 & k-means & OLS \\
\hline
\end{tabular}

Figure 12 to Figure 14 show the training and test results of the RBF network under three conditions: crack is in the middle of the rotor system $\left(c_{p}=10\right)$, crack is at the end of the rotor system $\left(c_{p}=1\right)$, and crack position is uncertain.

When the crack is located in the middle of the rotor system, it can be seen from Figure 12 (a) that the loss function of the training set, validation set, and test set all show an oscillating downward trend with the increase of the number of iterative steps, the loss function value of the validation set is minimized at 48th step and the training process terminates in advance at the 54th epoch. At the end of the training, the loss function value of the training set is $1.21 \times 10^{-5}$, the validation set is $3.16 \times 10^{-5}$, and the test set is $2.24 \times 10^{-5}$. All three values are reduced to $10^{-5}$ and with little difference, indicating that the RBF network has great generalization ability. Besides, it can be seen from Figure 12 (b) that the scatter points of the neural network 
1 output almost all fall on the ideal regression curve, and the37

2 correlation coefficient $\mathrm{R}$ between the output results of the 38

3 neural network and the sample results is 0.9985 , the39

4 maximum error is $1.8 \%$, which indicates that the RBF40

5 neural network output is almost linearly correlated with the4 1

6 sample results and the network has good performance. 42

7 According to the analysis results in Section 3, when the 43

8 crack is located in the middle of the rotor system at the 44

9 same dimensionless depth, the impact on the dynamic45

10 response of the rotor system is the greatest, and the change46

11 of critical speed and the peak of super-harmonic resonance47

12 is the largest. That is to say, the dynamic characteristics 48

13 related to the crack are the most obvious, so when the 49

14 crack is located in the middle of the rotor system, the RBF50 when the crack is located at the end of the rotor system,71 because of bearing and support with great rigidity, when72

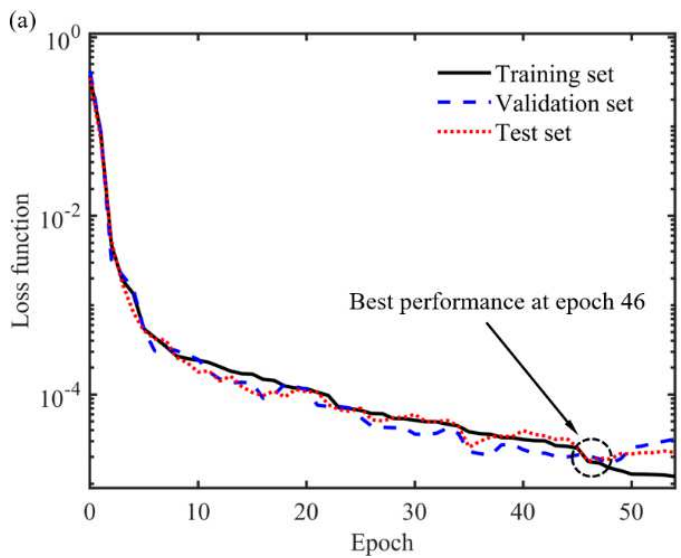
curve. (b) Regression output. the crack is shallow, the effect on the dynamic response of the rotor is relatively small, it leads to very insignificant dynamic characteristics such as critical speed changes and super-harmonic resonance peaks, which results in a decrease in the performance of the RBF network.

Moreover, Figure 12 and Figure 13 are the results of calculating the dimensionless crack depth when the crack position is fixed. However, in actual engineering problems, the crack may appear in various positions in the rotor system. Figure 14 shows training and test results of the RBF network when the crack position is uncertain. From Figure 14 it can be observed that during the training process, the loss function value of the training set oscillates and decays in a small range as the number of iteration steps increases, the loss function value of the validation set is minimized at the 48th epoch and training process terminates prematurely at 56th epoch. When the training is terminated, the loss function value of the training set is $2.19 \times 10^{-4}$, the test set is $2.23 \times 10^{-4}$. Both are relatively small and not very different, which indicates that the training effect is great and there is no serious overfitting. The performance of the RBF network can be seen more intuitively from the regression output results in Figure 14 (b), most of the regression output results are around the ideal regression curve and without significant deviation. The correlation coefficient $\mathrm{R}$ between the RBF network output and the sample result is 0.9916 , indicating that the linear correlation is very high, and the maximum error of the entire output result is $7.6 \%$. The above analysis results show that even when the crack location is uncertain, the RBF network can make good use of the dynamic characteristics such as first-order critical speed, first-order subcritical speed, first-order critical speed amplitude, and first-order super-harmonic resonance amplitude to diagnose the crack depth, and can achieve high precision.

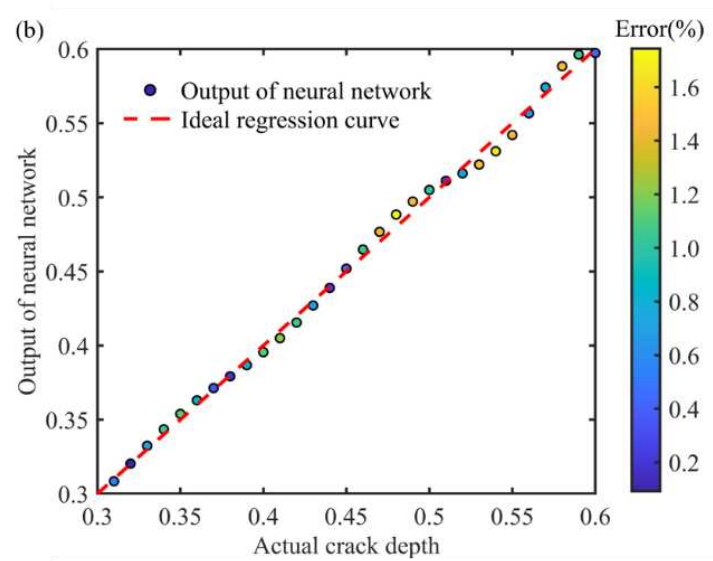

Figure 12 Training and test results of the RBF network when the crack is located in the middle of the rotor system: (a) Loss function 

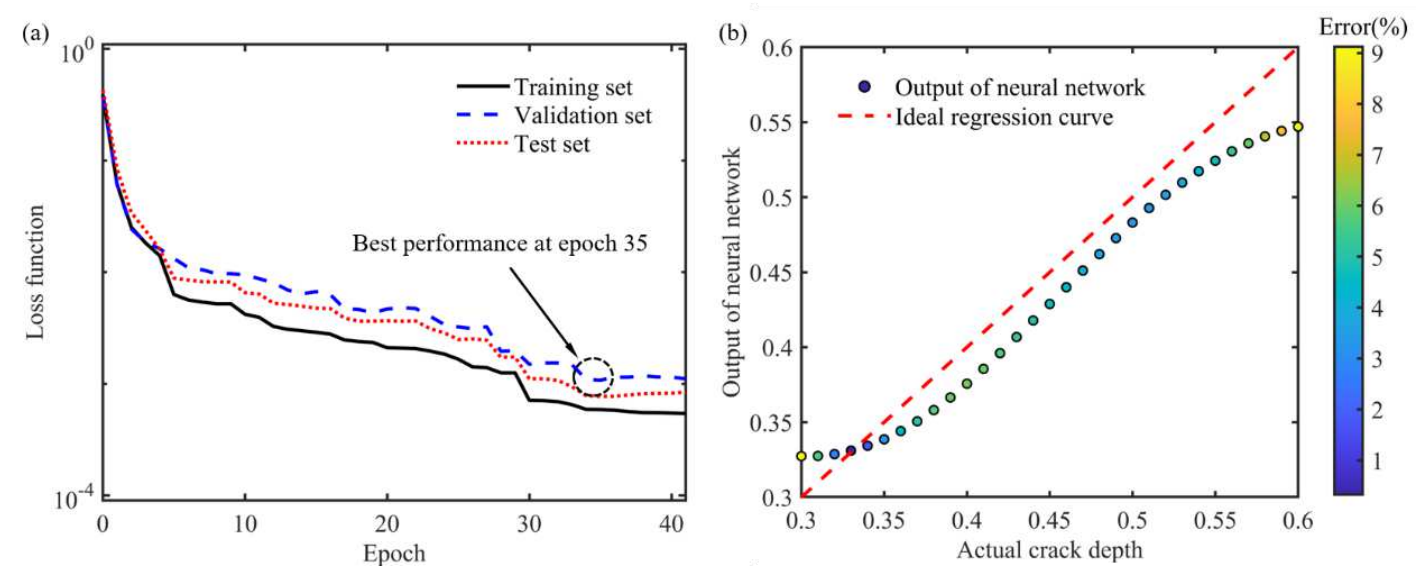

Figure 13 Training and test results of the RBF network when the crack is located at the end of the rotor system: (a) Loss function curve. (b) Regression output.
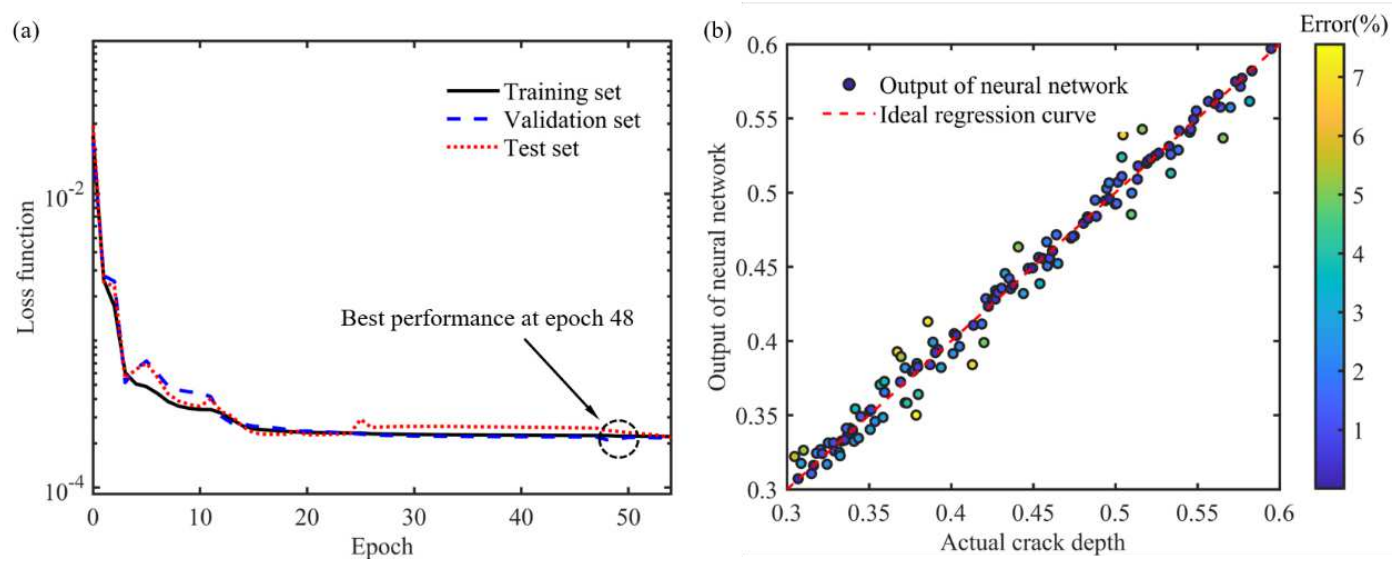

Figure 14 Training and test results of the RBF network when the crack position is uncertain: (a) Loss function curve. (b) Regression output.

\subsection{Pattern recognition neural network}

Pattern recognition neural network, hereinafter referred to as PRNN, is a kind of neural network which is adopted to 24 solve classification problem and its main structure is 25 shown in Figure 15.

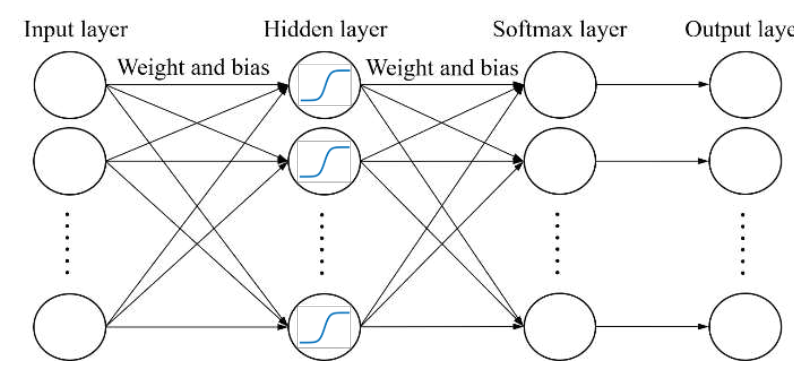

Figure 15 The structure of the pattern recognition network

The input first undergoes an affine transformation to the hidden layer, then it will be activated by the hidden layer 37 activation function. The most common activation function 38 used in the hidden layer of the PRN is the Tan-sigmoid function, which is given as

$$
f(x)=\frac{e^{x}-e^{-x}}{e^{x}+e^{-x}}
$$

The output after the activation function of the hidden layer will undergo an affine transformation to the Softmax layer again, and the function of the Softmax layer is to convert the output into a discrete probability density, which is obtained as

$$
y_{i}=\operatorname{softmax}\left(x_{i}\right)=\frac{\exp \left(x_{i}\right)}{\sum_{i=1}^{n} \exp \left(x_{i}\right)},
$$

where $\mathbf{x}=\left[x_{1}, x_{2}, \ldots, x_{\mathrm{n}}\right]^{\mathrm{T}}$ is the input vector. From equation (22) we can see that the output vector $\mathbf{y}=\left[y_{1}, y_{2}, \ldots, y_{\mathrm{m}}\right]^{\mathrm{T}}$ is non-negative and the sum of $\mathbf{y}$ is 1 after the softmax layer and it is the property of the discrete probability density. Generally, we take the location of the maximum 
1 probability density as the result of classification, for45

2 example, if the output result of PRNN for input is [0.1, 0.6,46

3 0.3], it is considered that this input should be classified47

4 into the second category. where $P\left(x_{\mathrm{i}}\right)$ is the actual probability distribution of event $x_{\mathrm{i}}, 56$ it is a sparse vector in the classification problem where the 57 position of the category is 1 and all the other elements are 58 0. $Q\left(x_{\mathrm{i}}\right)$ is the discrete probability density of event $x_{\mathrm{i}}$ output ${ }^{59}$ by PRNN. Some other training parameters are shown in60 Table 5. The number of hidden neurons is 15 , the steps of 61 validation failure are 6 which means that the training62 process is terminated when the loss function of the 63 validation set is no longer descending for 6 consecutive 64 times, the initial learning rate is 0.001 and the training 65 algorithm adopts Levenberg-Marquardt backpropagation 66 (L-M) which takes up more storage space but is faster. $\quad 67$

Table 5 Training parameters of PRNN

\begin{tabular}{ccccccc}
\hline $\begin{array}{c}\text { Loss } \\
\text { function }\end{array}$ & $\begin{array}{c}\text { Number } \\
\text { of hidden } \\
\text { neurons }\end{array}$ & $\begin{array}{c}\text { Max } \\
\text { epochs }\end{array}$ & $\begin{array}{c}\text { Steps of } \\
\text { validation } \\
\text { failure }\end{array}$ & $\begin{array}{c}\text { Initial } \\
\text { learning } \\
\text { rate }\end{array}$ & $\begin{array}{c}\text { Training } \\
\text { algorithm }\end{array}$ & $\begin{array}{c}71 \\
72\end{array}$ \\
\hline $\begin{array}{c}\text { Cross } \\
\text { entropy }\end{array}$ & 15 & 100 & 6 & 0.001 & L-M & $\begin{array}{l}73 \\
74\end{array}$ \\
\hline
\end{tabular}

Based on these parameters, the loss function curve of 76 training and test are shown in Figure 16. It can be $\operatorname{seen}^{77}$ from Figure 16 that the loss function of the training set, ${ }^{78}$ validation set, and test set oscillates and decreases with the ${ }^{79}$ increase in the number of iteration epochs during the 80 training process, the loss function value of the validation 81 set is minimized at 66th step and the training process 82 terminates in advance at the $72 \mathrm{nd}$ epoch. At this time, the ${ }^{83}$ loss function value of the training set is 0.0147 , the validation set is. 0.0390 and the test set is 0.04148 . The loss function value of the training set and the test set are close, indicating that the neural network has good generalization ability. The recognition accuracy of PRNN in the test set and validation set at the end of training is $78.6 \%$. The basic requirements of crack location fault diagnosis are achieved.

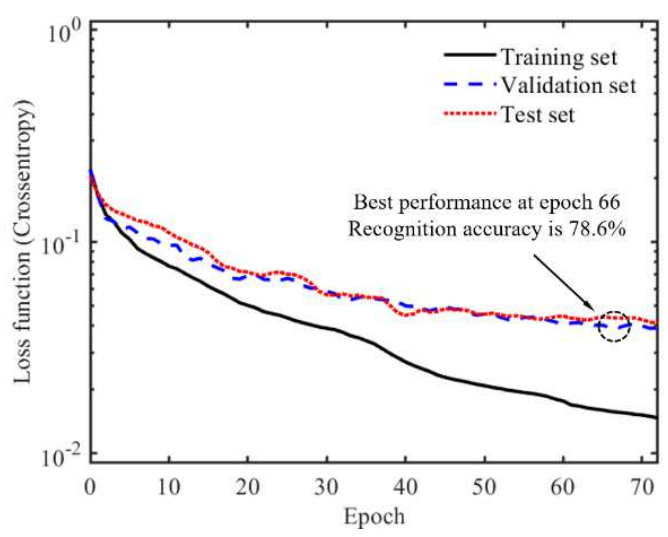

Figure 16 The loss function curve of PRNN in the training process

Moreover, the problem of classification not only needs to pay attention to the correct situation of classification to achieve relatively high recognition accuracy but also needs to concentrate on the causes of classification error. Figure 17 shows the part of the confusion matrix of PRNN results with the misclassification category. As we can see from Figure 17, most of the elements of the confusion matrix are concentrated on the diagonals (dashed area), which means that the PRNN accurately identifies the location of the crack. And careful analysis of the misclassified elements in the confusion matrix can be found that most of the incorrectly classified PRNN output values are only one unit away from the actual position of the crack, for example, there are 4 cracks in element 15 actually which are identified in element 14 and 3 cracks in element 13 actually which are recognized in element 12 by PRNN. This is because the dynamic characteristics, including the first critical whirl speed, the first subcritical speed, the first critical speed amplitude, and the super-harmonic resonance peak at $1 / 2$ first critical whirl speed, are related to both crack depth and position, which will confuse the PRNN when it comes to classification. But when the shaft is divided into 20 elements, the element length is very small, therefore, the deviation of 1 element length in determining the crack location will not cause a serious problem. Based on the consideration of this factor, the condition for 
1 calculating the recognition accuracy can be extended to the 9

2 recognition deviation within 1 element length, which10

3 means that if the output of the PRNN is 12 or 14 and the 1

4 actual crack position is 13 , it can also be considered that 2

5 the output of the PRNN is approximately accurate. In this13

6 condition, it can be seen from Figure 17 that almost all the14

7 elements in the confusion matrix fall in the approximate 15

8 accurate area and only 1 element of the 56 samples has a recognition deviation of 2 element lengths (actual crack location is 15 but the PRNN output is 13), the approximate recognition accuracy is $98.2 \%$. These above analysis results show that PRNN can make great use of the dynamic response characteristics of the cracked rotor system to diagnose the crack position and achieve a high approximate identification accuracy.

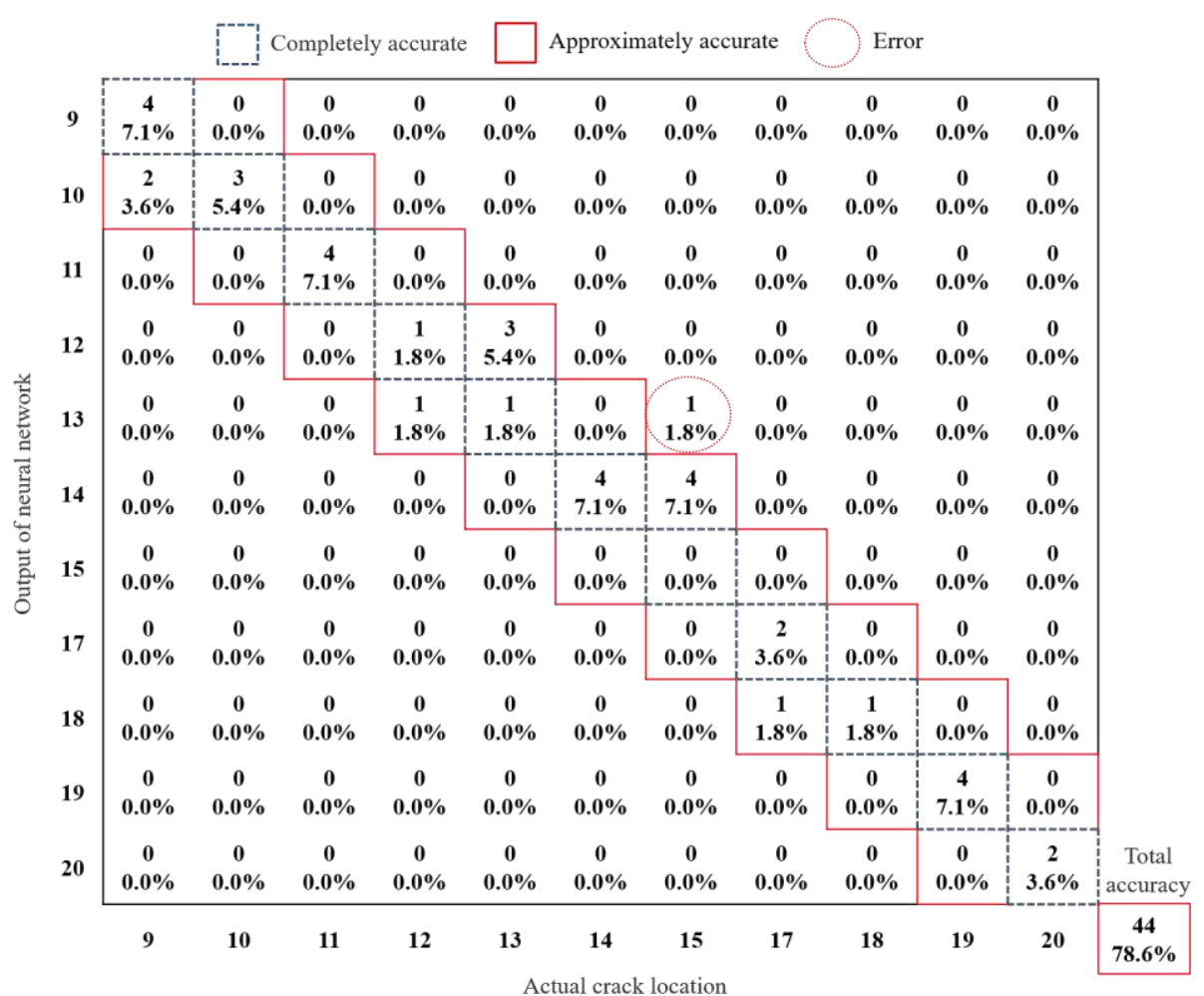

Figure 17 The part of the confusion matrix of PRNN results with misclassification category

\section{Conclusions}

In this paper, a dual-disks rotor system model with a breathing crack suitable for short-thick hollow shaft rotors has been established based on the finite element method and Timoshenko beam theory. The dynamic response of the cracked rotor system has been obtained by using the fourth-order harmonic balance method. Then, a new crack fault diagnosis and location method for the dual-disk hollow shaft rotor system based on the RBF network and PRNN has been proposed. The simulation results show that this method has high fault diagnosis accuracy. The main conclusions are as follows.

(1) The crack will cause the rotor system to appear super-harmonic phenomenon near $1 / n(n=2,3,4)$ first critical speed and the first critical whirl speed to drop slightly. In addition, the super-harmonic resonance peak values in the amplitude-frequency response and the first-order critical speed of the rotor system are closely related to the dimensionless depth and position of the crack. The greater the crack depth is, the closer it is to the central part of the rotor system, the greater the influence it has on the dynamic response of the rotor system.

(2) Based on the RBF network and PRNN, the fault diagnosis of the crack depth and position is carried out by using the first critical whirl speed, the first subcritical speed, the first critical speed amplitude, and the super-harmonic resonance peak at 1/2 first critical whirl speed. The results show that when the depth and position of the crack are both uncertain, the maximum error of the dimensionless crack depth calculated by the $\mathrm{RBF}$ network is $7.56 \%$, and the approximate 
recognition accuracy of the crack position obtained by PRNN can reach $98.2 \%$, the requirements of crack fault diagnosis are satisfied preliminarily.

(3) The rotor system model established in this study is suitable for short and thick hollow shaft rotor and can be used for accurate fault diagnosis under the circumstance of uncertain crack depth and position, which can provide a reference for rotor crack fault diagnosis in practical engineering problems.

\section{Declaration}

\section{Acknowledgements}

Not applicable.

\section{Funding}

Supported by National Science and Technology Major Project of China (Grant No. 2017-IV-0008-0045), and National Natural Science Foundation of China (Grant No. 11972129).

\section{Availability of data and materials}

The datasets supporting the conclusions of this article are included within the article.

\section{Authors' contributions}

The authors' contributions are as follows: Yu-Hong Jin was in charge of the whole analyses and wrote the manuscript; Lei Hou assisted with sample analyses and revised the manuscript; Zhen-Yong Lu assisted with simulation analyses; Yu-Shu Chen revised the final manuscript. All authors read and approved the final manuscript.

\section{Competing interests}

The authors declare no competing financial interests.

\section{Consent for publication}

Not applicable.

\section{Ethics approval and consent to participate}

Not applicable.

\section{References}

[1] I W Mayes, W G R Davies. Analysis of the response of a multi-rotor-bearing system containing a transverse crack in a rotor. Journal of Vibration and Acoustics, 1984, 106(1): 139-145.

[2] M A Al-Shudeifat, E A Butcher, R C Stern. General harmonic balance solution of a cracked rotor-bearing-disk system for harmonic and sub-harmonic analysis: Analytical and experimental approach. International Journal of Engineering Science, 2010, 48(10): 921-935.
[3] M A Al-Shudeifat, E A Butcher. New breathing functions for the transverse breathing crack of the cracked rotor system: approach for critical and subcritical harmonic analysis. Journal of Sound and Vibration, 2011, 330(3): 526-544.

[4] O S Jun, H J Eun, Y Y Earmme, et al. Modelling and vibration analysis of a simple rotor with a breathing crack. Journal of Sound and Vibration, 1992, 155(2): 273-290.

[5] T R Babu, S Srikanth, A S Sekhar. Hilbert-Huang transform for detection an monitoring of crack in a transient rotor. Mechanical Systems and Signal Processing, 2008, 22: 905-914.

[6] A C Chasalevris, C A Papadopoulos. Coupled horizontal and vertical bending vibrations of a stationary shaft with two cracks. Journal of Sound and Vibration, 2008, 309(3-5): 507-528.

[7] A K Darpe, K Gupta, A Chawla. Dynamics of a two-crack rotor. Journal of Sound and Vibration, 2003, 259(3): 649-675.

[8] L Xiang, L Gao x, A Hu. Nonlinear dynamics of an asymmetric rotor-bearing system with coupling faults of crack and rub-impact under oil-film forces. Nonlinear Dynamics, 2016, 86(2): 1057-1067.

[9] L Hou, Y S Chen. Super-harmonic responses analysis for a cracked rotor system considering inertial excitation. Science China Technological Sciences, 2015, 58(11): 1924-1934.

[10] Hou L, Y S Chen, Z Y Lu, et al. Bifurcation analysis for 2: 1 and 3: 1 super-harmonic resonance of an aircraft cracked rotor system due to maneuver load. Nonlinear Dynamics, 2015, 81(1-2): 531-547.

[11] Z Y Lu, L Hou, Y S Chen, et al. Nonlinear response analysis for a dual-rotor system with a breathing transverse crack in the hollow shaft. Nonlinear Dynamics, 2016, 83(1-2): 169-185.

[12] C Fu, Y Xu, Y Yang, et al. Dynamics analysis of a hollow-shaft rotor system with an open crack under model uncertainties. Communications in Nonlinear Science and Numerical Simulation, 2020, 83(1): 102-115.

[13] F Jia, Y Lei, J Lin, et al. Deep neural networks: A promising tool for fault characteristic mining and intelligent diagnosis of rotating machinery with massive data. Mechanical Systems and Signal Processing, 2016, 72(3): 303-315.

[14] J Yan, C Z Guo, X Wang, et al. A data-driven neural network approach for remaining useful life prediction. Key Engineering Materials, 2011, 450: 544-547.

[15] W X Lai, P W Tse, G C Zhang, et al. Classification of gear faults using cumulants and the radial basis function network. Mechanical Systems and Signal Processing, 2004, 18(2): 381-389.

[16] C Z Guo, M A Al-Shudeifat, J Yan, et al. Application of Empirical Mode Decomposition to a Jeffcott Rotor with a Breathing Crack. Journal of Sound and Vibration, 2013, 332: 3881-3892.

[17] C Z Guo, J Yan, W Yang. Crack detection for a Jeffcott rotor with a transverse crack: An experimental investigation. Mechanical Systems and Signal Processing, 2017, 83, 260-271.

[18] R K Vashisht, Q Peng. Crack detection in the rotor ball bearing system using switching control strategy and Short Time Fourier Transform. Journal of Sound and Vibration, 2018, 432, 502-529.

[19] K K Pavan, C Satish, S P Harsha. Vibration-based fault diagnosis of a rotor bearing system using artificial neural network and support vector machine. International Journal of Modelling, Identification and Control, 2012, 15(3), 185-198.

[20] G F Bin, J J Gao, X J Li, et al. Early fault diagnosis of rotating machinery based on wavelet packets-Empirical mode decomposition feature extraction and neural network. Mechanical Systems and Signal Processing, 2012, 27, 696-711.

[21] S Ma, F Chu. Ensemble deep learning-based fault diagnosis of rotor bearing systems. Computers in Industry, 105, 143-152. 
[22] D Wang, C Hua, D Dong, et al. Crack parameters identification based on a kriging surrogate model for operating rotors. Shock and Vibration, 2018.

[23] Zhang S, Asakura T, Xu X, et al. Fault diagnosis system for rotary machine based on fuzzy neural networks [J]. JSME International Journal Series C, 2003, 46(3), 1035-1041.

[24] L M Wang, Y M Shao. Crack Fault Classification for Planetary Gearbox Based on Feature Selection Technique and K-means Clustering Method. Chinese Journal of Mechanical Engineering, 2018, 31(4), 200-210.

[25] B Li, X F Chen, Z J He. Three-steps-meshing based multiple crack identification for structures and its experimental studies. Chinese Journal of Mechanical Engineering, 2013, 26, 400-405.

[26] J J Sinou, A W Lee. A non-liner study of a cracked rotor. European Journal of Mechanics A/Solid, 2007, 26(1): 152-170.

\section{Biographical notes}

Yu-Hong Jin, born in 1998, is currently a master candidate at School of Astronautics, Harbin Institute of Technology, China. His research interests include machine learning and nonlinear dynamics.

E-mail: 20s018042@stu.hit.edu.cn

Lei Hou, born in 1987, is currently an associate professor and a PhD candidate supervisor at School of Astronautics, Harbin Institute of Technology, China. He received his $\mathrm{PhD}$ degree from Harbin Institute of Technology, China, in 2015. His main research interests include nonlinear dynamics, rotor dynamics, vibration control, fault diagnosis.

E-mail: houlei@ hit.edu.cn

Zhen-Yong Lu, born in 1988, is currently a lecturer at Institute of Dynamics and Control Science, Shandong Normal University, China. He received his $\mathrm{PhD}$ degree from Harbin Institute of Technology, China, in 2017. His research interests include nonlinear dynamics, rotor dynamics, crack fault diagnosis.

E-mail: luzy@sdnu.edu.cn

Yu-Shu Chen, born in 1931, is currently a professor and a PhD candidate supervisor at School of Astronautics, Harbin Institute of Technology, China. His main research interests include nonlinear dynamics and its applications in engineering.

E-mail: yschen@ hit.edu.cn

\section{Appendix}

Timoshenko beam finite element matrices in equation (13)

$\mathbf{K}_{\mathrm{s}}^{\mathbf{c}}=\frac{E I}{\left(1+\varphi_{s}^{2}\right) l^{3}}\left[\begin{array}{ccccccccc}K_{s 1}^{c} & & & & & & & s y m . \\ 0 & K_{s 1}^{c} & & & & & & \\ 0 & -K_{s 2}^{c} & K_{s 3}^{c} & & & & & \\ -K_{s 2}^{c} & 0 & 0 & K_{s 3}^{c} & & & & \\ -K_{s 1}^{c} & 0 & 0 & K_{s 2}^{c} & K_{s 1}^{c} & & & \\ 0 & -K_{s 1}^{c} & K_{s 2}^{c} & 0 & 0 & K_{s 1}^{c} & & \\ 0 & -K_{s 2}^{c} & K_{s 4}^{c} & 0 & 0 & K_{s 2}^{c} & K_{s 3}^{c} & \\ -K_{s 2}^{c} & 0 & 0 & K_{s 4}^{c} & K_{s 2}^{c} & 0 & 0 & K_{s 3}^{c}\end{array}\right]$

$K_{s 1}^{c}=12$

$K_{s 2}^{c}=6 l$
$K_{s 3}^{c}=\left(4+2 \varphi_{s}+\varphi_{s}^{2}\right) l^{2}$

$K_{s 4}^{c}=\left(2-2 \varphi_{s}-\varphi_{s}^{2}\right) l^{2}$

$\xi=\frac{z}{l}, \varphi_{s}=\frac{12 E I}{\mu A G l^{2}}$

$\mathbf{K}_{\mathrm{s}}^{\mathbf{c}}=\frac{E I \varphi_{s}}{\left(1+\varphi_{s}^{2}\right) l^{3}}\left[\begin{array}{ccccccccc}K_{s 1}^{s} & & & & & & & s y m . \\ 0 & K_{s 1}^{s} & & & & & & \\ 0 & -K_{s 2}^{s} & K_{s 3}^{s} & & & & & \\ -K_{s 2}^{s} & 0 & 0 & K_{s 3}^{s} & & & & \\ -K_{s 1}^{s} & 0 & 0 & K_{s 2}^{s} & K_{s 1}^{s} & & & \\ 0 & -K_{s 1}^{s} & K_{s 2}^{s} & 0 & 0 & K_{s 1}^{s} & & \\ 0 & -K_{s 2}^{s} & K_{s 3}^{s} & 0 & 0 & K_{s 2}^{s} & K_{s 3}^{s} & \\ -K_{s 2}^{s} & 0 & 0 & K_{s 3}^{s} & K_{s 2}^{s} & 0 & 0 & K_{s 3}^{s}\end{array}\right]$

$K_{s 1}=12 K_{s 2}=6 l, K_{s 3}=\left(2-\varphi_{s}\right) l^{2}, K_{s 4}=\left(4+\varphi_{s}\right) l^{2}$

$\mathbf{M}_{\mathrm{s}}^{\mathbf{c}}=\frac{\rho_{s} l}{\left(1+\varphi_{s}^{2}\right)}\left[\begin{array}{ccccccccc}M_{s 1}^{c} & & & & & & & s y m . \\ 0 & M_{s 1}^{c} & & & & & & \\ 0 & -M_{s 4}^{c} & M_{s 2}^{c} & & & & & \\ -M_{s 4}^{c} & 0 & 0 & M_{s 2}^{c} & & & & \\ M_{s 3}^{c} & 0 & 0 & -M_{s 5}^{c} & M_{s 1}^{c} & & & \\ 0 & M_{s 3}^{c} & -M_{s 5}^{c} & 0 & 0 & M_{s 1}^{c} & & \\ 0 & M_{s 5}^{c} & -M_{s 6}^{c} & 0 & 0 & M_{s 4}^{c} & M_{s 2}^{c} & \\ M_{s 5}^{c} & 0 & 0 & -M_{s 6}^{c} & M_{s 4}^{c} & 0 & 0 & M_{s 2}^{c}\end{array}\right]$

$M_{s 1}^{c}=13 / 35+7 / 10 \varphi_{s}+\varphi_{s}^{2}$

$M_{s 2}^{c}=\left(1 / 105+1 / 60 \varphi_{s}+1 / 120 \varphi_{s}^{2}\right) l^{2}$

$M_{s 3}^{c}=9 / 70+3 / 10 \varphi_{s}+1 / 6 \varphi_{s}^{2}$

$M_{s 4}^{c}=\left(11 / 210+11 / 120 \varphi_{s}+1 / 24 \varphi_{s}^{2}\right) l$

$M_{s 5}^{c}=\left(13 / 420+3 / 40 \varphi_{s}+1 / 24 \varphi_{s}^{2}\right) l$,

$M_{s 6}^{c}=\left(1 / 140+1 / 60 \varphi_{s}+1 / 120 \varphi_{s}^{2}\right) l^{2}$

$\mathbf{M}_{\mathrm{s}}^{\mathrm{s}}=\frac{j_{d}}{\left(1+\varphi_{s}^{2}\right) l}\left[\begin{array}{ccccccccc}M_{s 1}^{s} & & & & & & & s y m . \\ 0 & M_{s 1}^{s} & & & & & & \\ 0 & -M_{s 4}^{s} & M_{s 2}^{s} & & & & & \\ -M_{s 4}^{s} & 0 & 0 & M_{s 2}^{s} & & & & \\ -M_{s 1}^{s} & 0 & 0 & -M_{s 4}^{s} & M_{s 1}^{s} & & & \\ 0 & -M_{s 1}^{s} & M_{s 4}^{s} & 0 & 0 & M_{s 1}^{s} & & \\ 0 & -M_{s 4}^{s} & M_{s 3}^{s} & 0 & 0 & -M_{s 4}^{s} & M_{s 2}^{s} & \\ -M_{s 4}^{s} & 0 & 0 & M_{s 3}^{s} & -M_{s 4}^{s} & 0 & 0 & M_{s 2}^{s}\end{array}\right]$

$M_{s 1}^{s}=6 / 5, M_{s 2}^{s}=\left(2 / 15+1 / 6 \varphi+1 / 3 \varphi^{2}\right) l^{2}$,

$M_{s 3}^{s}=\left(-1 / 30-1 / 6 \varphi+1 / 6 \varphi^{2}\right) l^{2}, M_{s 4}^{s}=(1 / 10-1 / 2 \varphi) l$

$\mathbf{J}_{\mathbf{s}}=\frac{j_{p}}{30\left(1+\varphi_{s}^{2}\right) l}\left[\begin{array}{cccccccc}0 & & & & & & & \text { antisym. } \\ J_{s 1} & 0 & & & & & & \\ -J_{s 2} & 0 & 0 & & & & & \\ 0 & -J_{s 2} & J_{s 4} & 0 & & & & \\ 0 & J_{s 1} & -J_{s 2} & 0 & 0 & & & \\ -J_{s 1} & 0 & 0 & -J_{s 2} & J_{s 1} & 0 & & \\ -J_{s 2} & 0 & 0 & J_{s 3} & J_{s 2} & 0 & 0 & \\ 0 & -J_{s 1} & -J_{s 3} & 0 & 0 & J_{s 2} & J_{s 4} & 0\end{array}\right]$

$J_{s 1}=36$

$J_{s 2}=3 l-15 l \varphi_{s}$

$J_{s 3}=l^{2}+5 l^{2} \varphi_{s}-15 l^{2} \varphi_{s}^{2}$ 
$J_{s 4}=4 l^{2}+5 l^{2} \varphi_{s}+10 l^{2} \varphi_{s}^{2}$ 


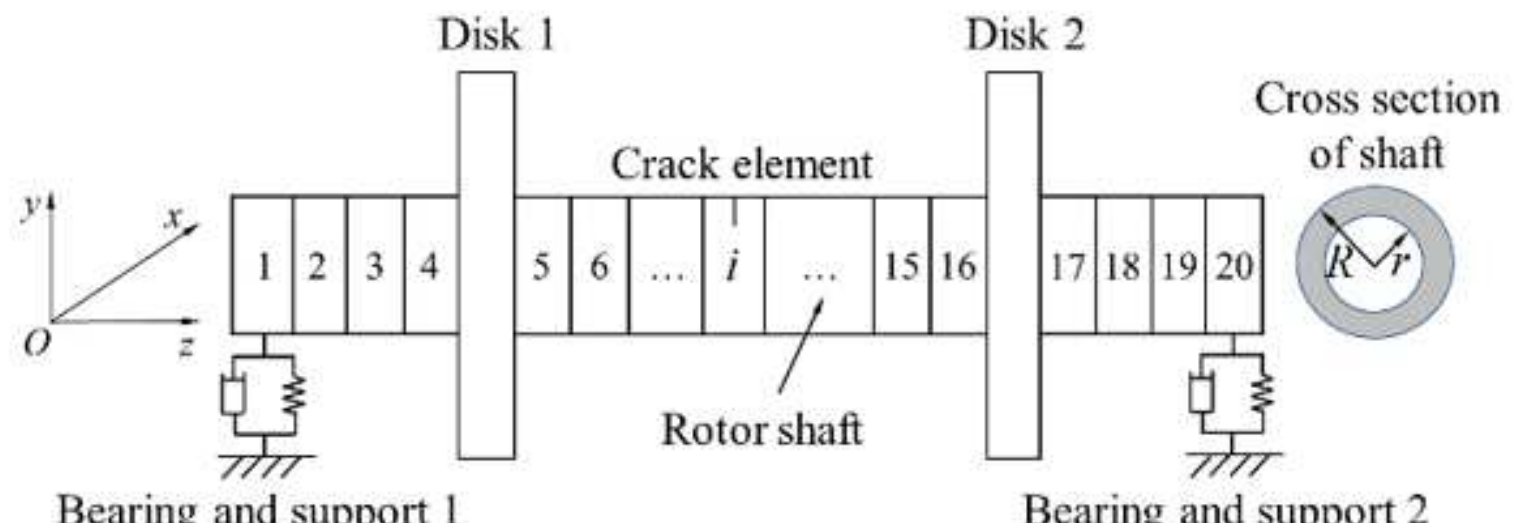

Bearing and support 1

Bearing and support 2

\section{Figure 1}

Finite element model of a cracked two-disk hollow shaft rotor system

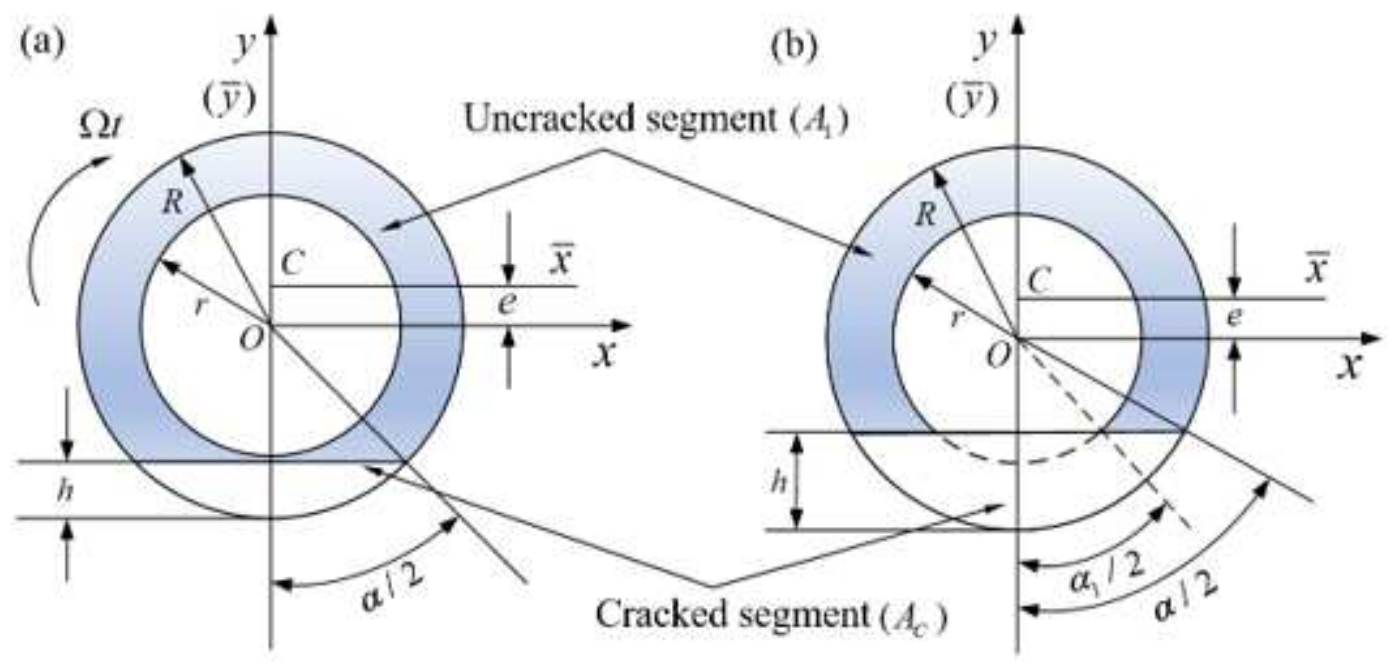

Figure 2

Cross-section diagram of hollow shaft crack: (a) Non-penetrating crack. (b) Passthrough crack. The dashed area represents the uncracked segment 


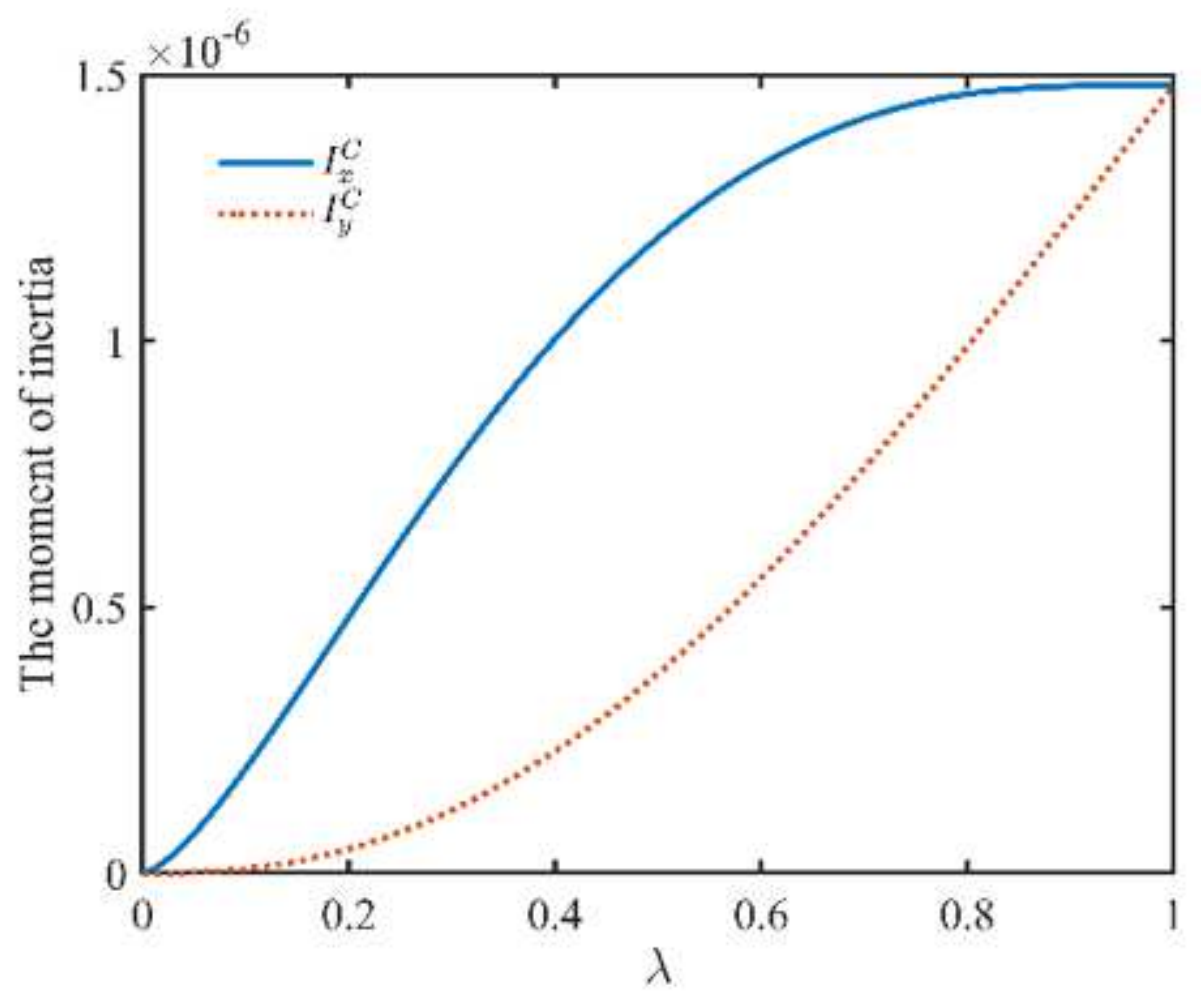

Figure 3

The curve of $I \_x^{\wedge} C$ and $I \_y^{\wedge} C$ with respect to $\lambda(R=1, r=0.5)$

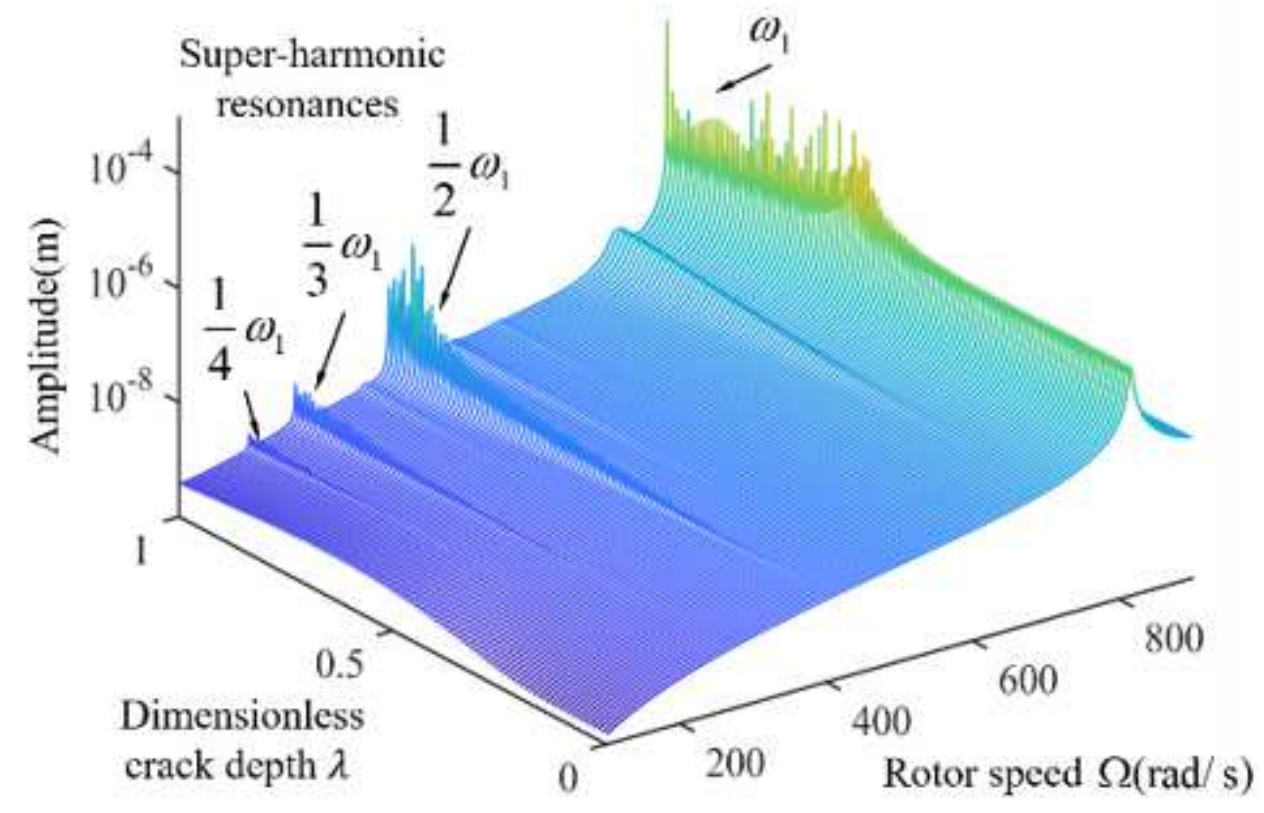

Figure 4

3D waterfall diagram of rotor speed-dimensionless crack depth-amplitude at node $10(\mathrm{cp}=10)$ 


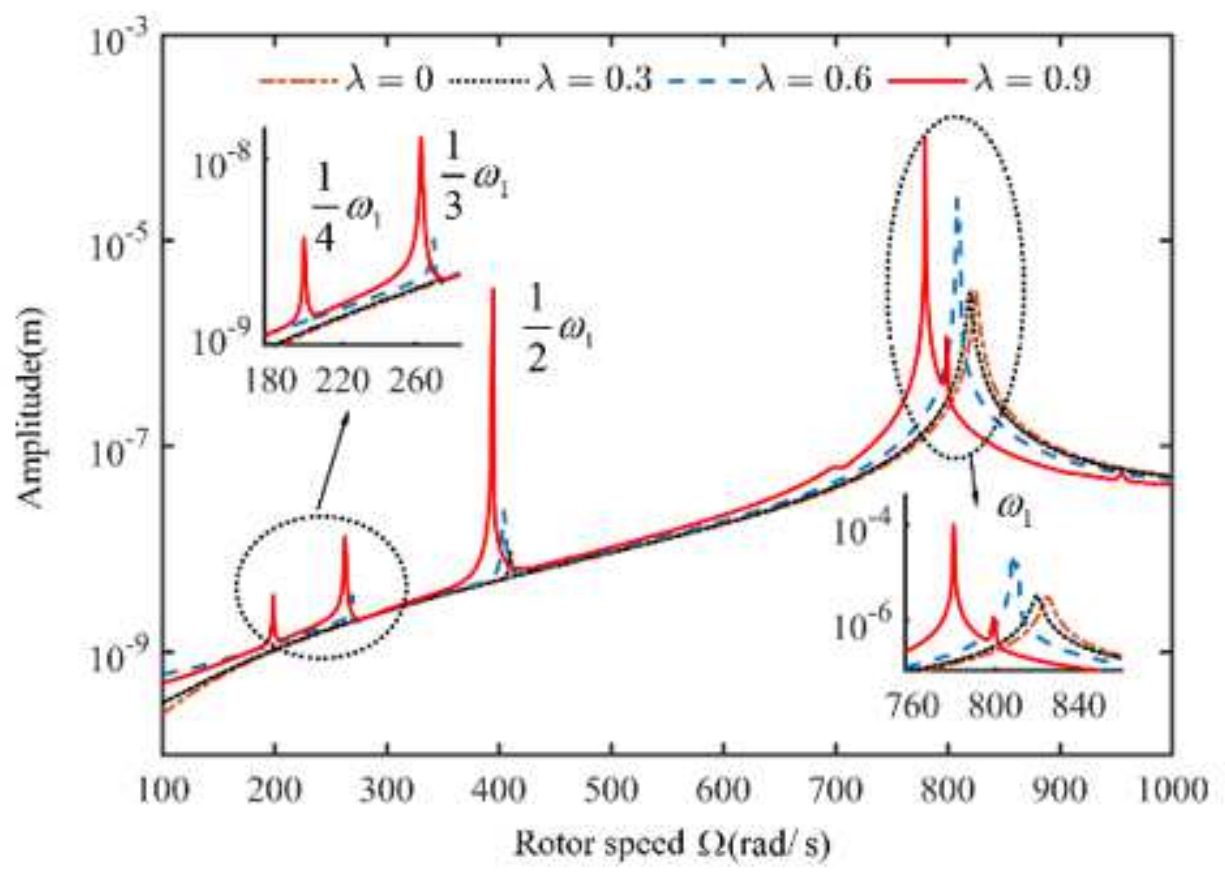

Figure 5

Amplitude-frequency response curves for different crack depth at node $10(\mathrm{cp}=10)$

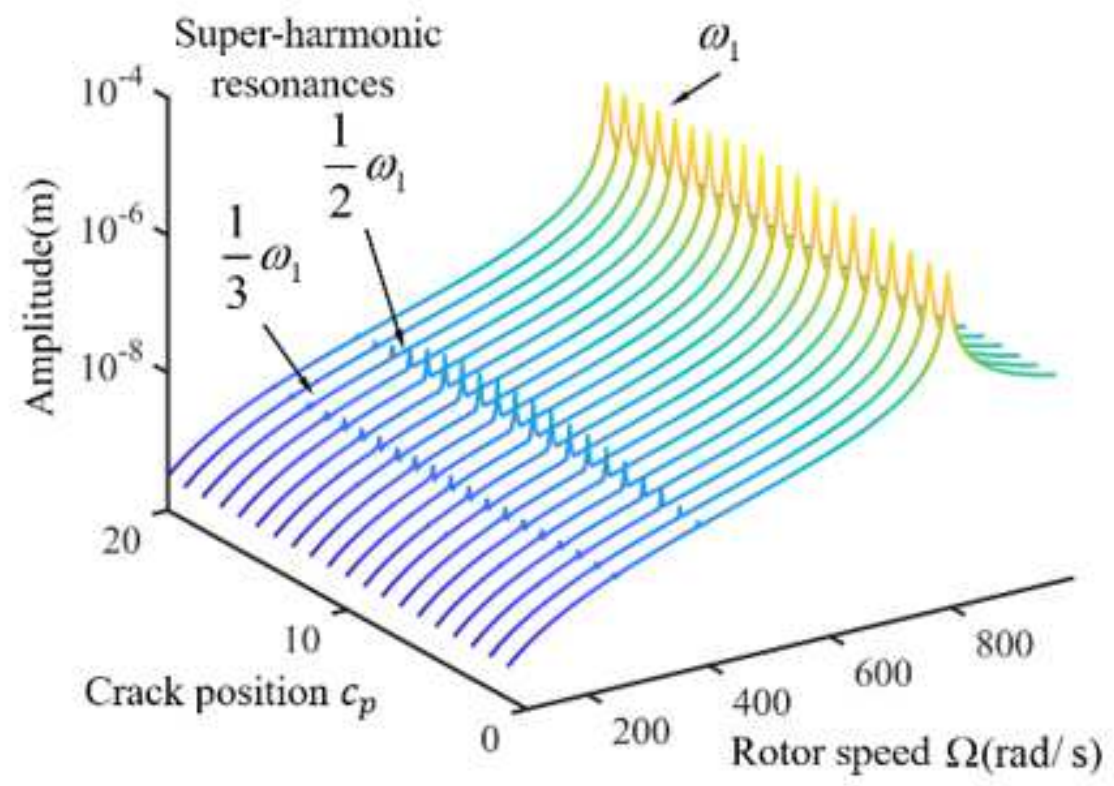

Figure 6

3D waterfall diagram of rotor speed-crack position-amplitude at node $10(\lambda=0.5)$ 


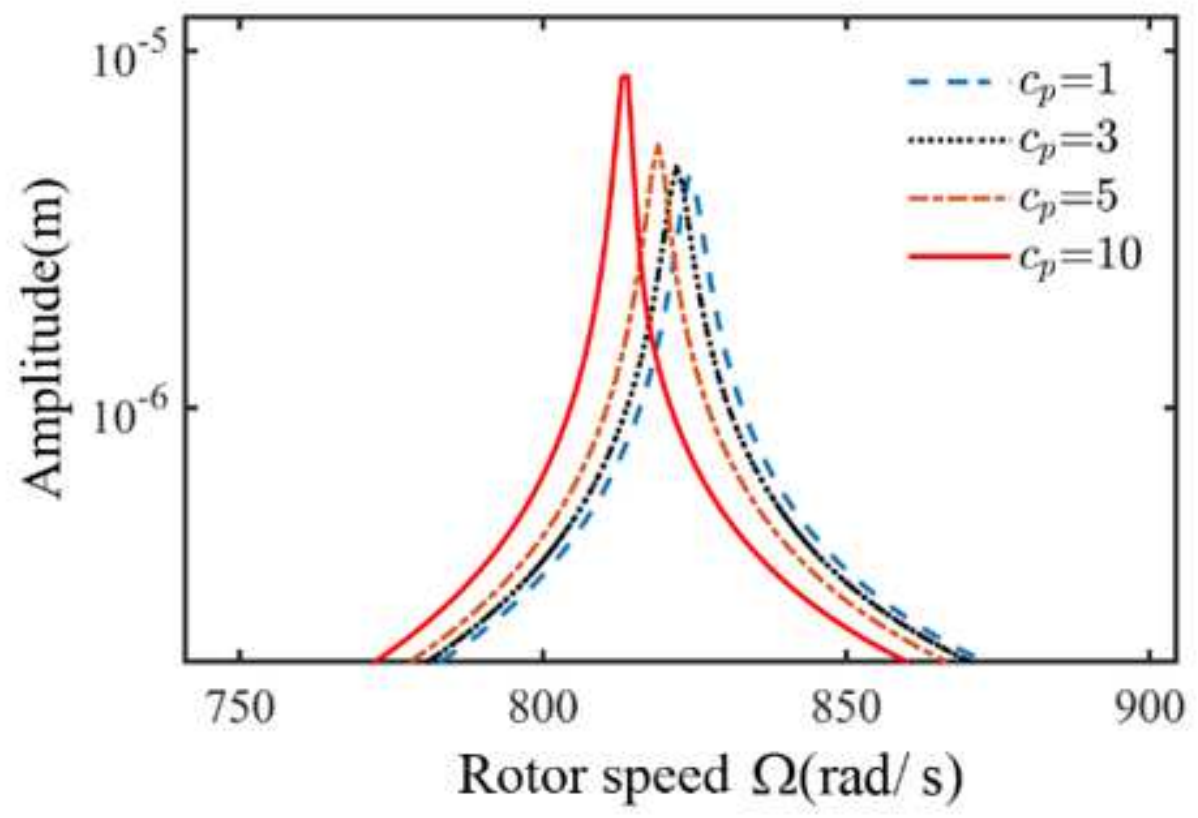

Figure 7

Amplitude-frequency response curves for different crack position at node $10(\lambda=0.5)$

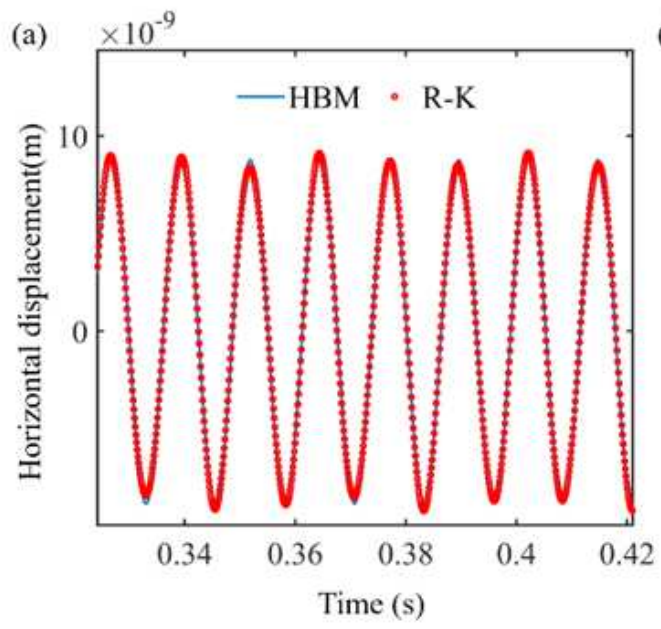

(b) $\times 10^{-8}$

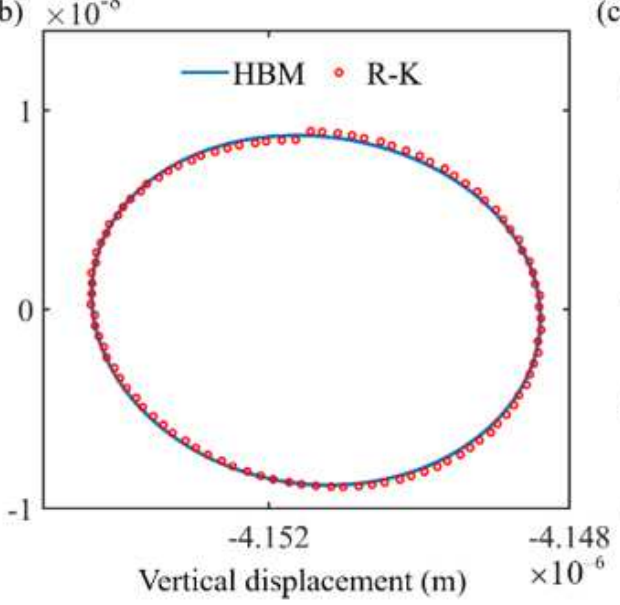

(c) $\times 10^{-9}$

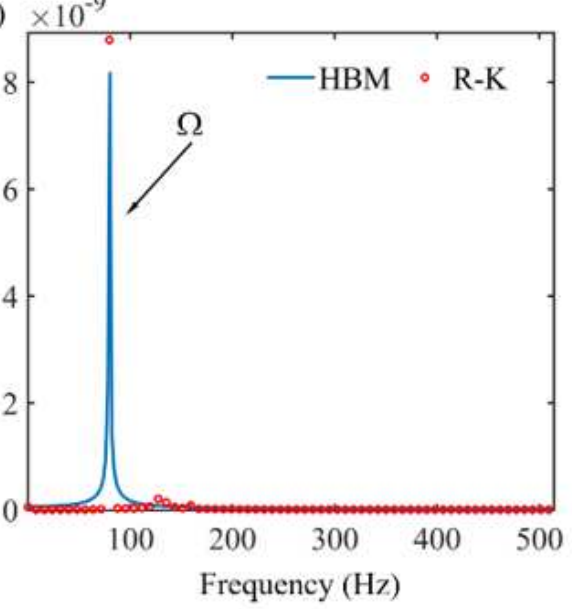

Figure 8

Comparison of time history, whirling orbits, and frequency spectrum for $\lambda=0.3, c_{-} p=10$ and $\Omega=500 \mathrm{rad} / \mathrm{s}$ at node 10: (a) Time history. (b) Whirling orbits. (c) Frequency spectrum. 

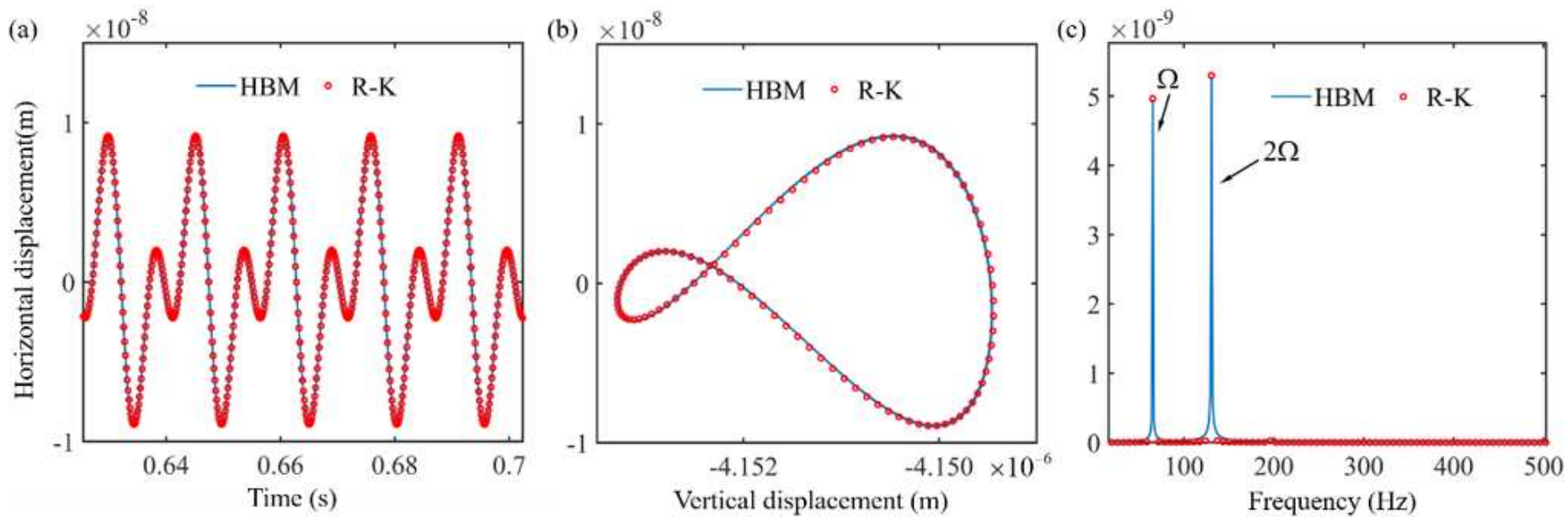

Figure 9

Comparison of time history, whirling orbits, and frequency spectrum for $\lambda=0.3, c_{-} p=10$ and $\Omega=410 \mathrm{rad} / \mathrm{s}$ $\approx 1 \backslash / 2 \omega_{-} 1$ at node 10: (a) Time history. (b) Whirling orbits. (c) Frequency spectrum. 
(a) Input layer Hidden layer 1 Hidden layer 2

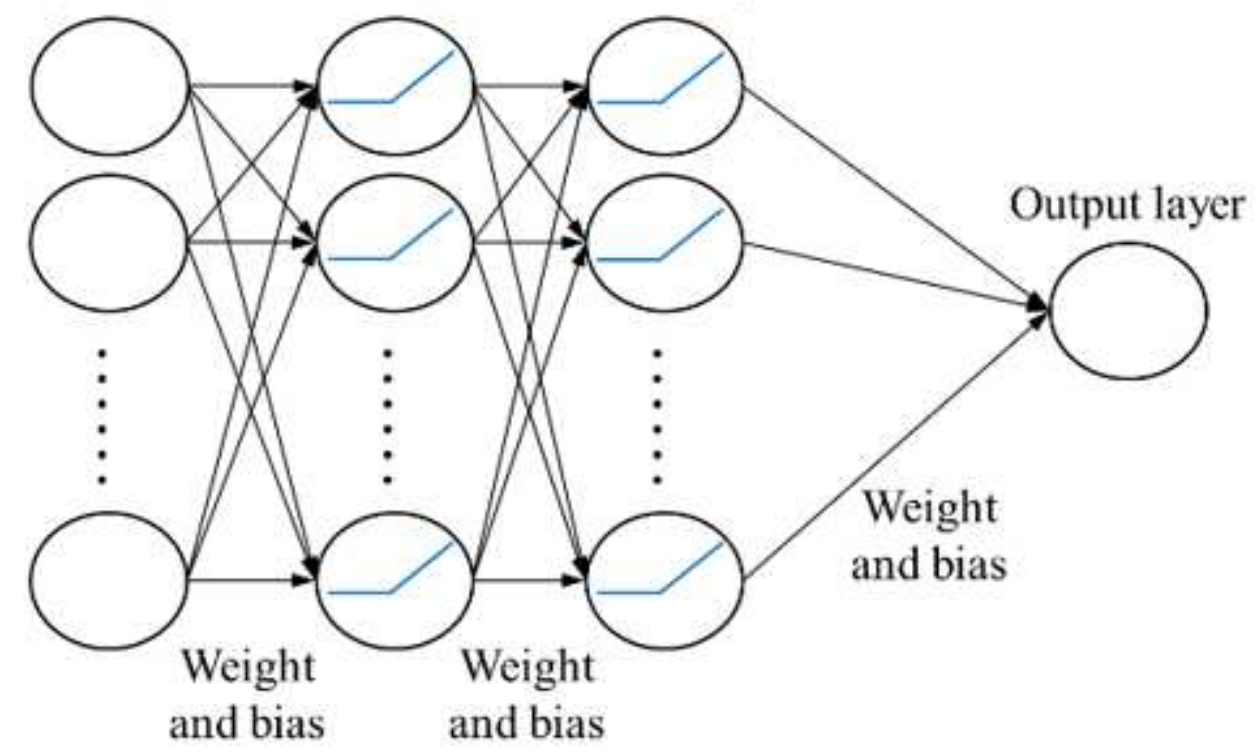

(b) Input layer

Hidden layer

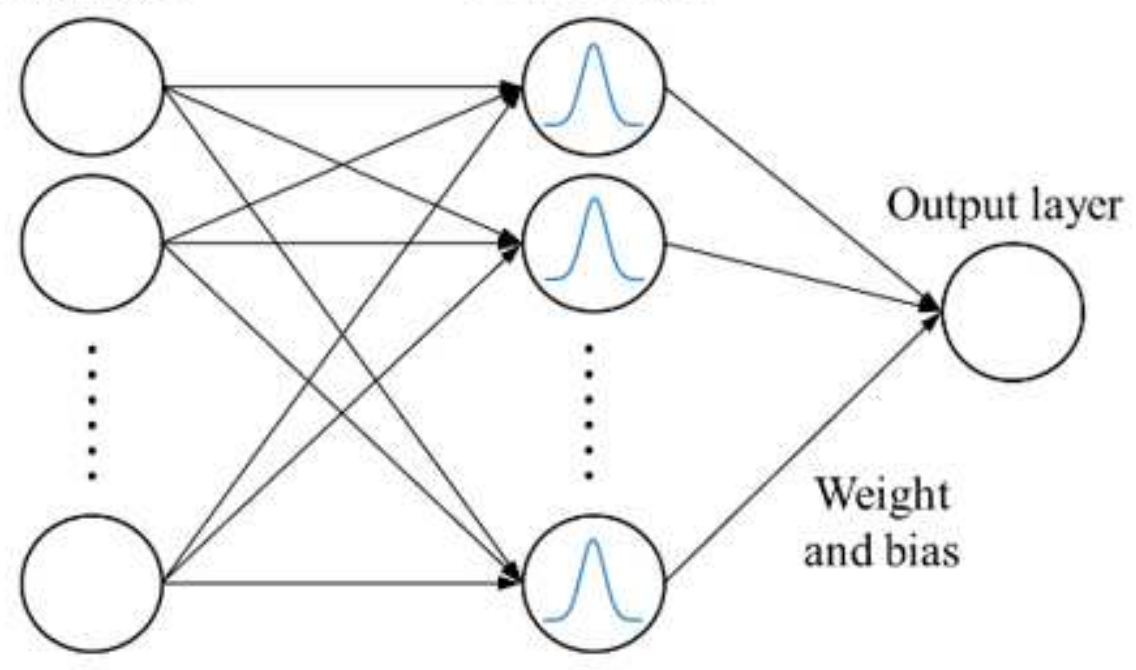

Direct connection

Figure 10

Structure of RBF and BP neural network: (a) RBF neural network. (b) BP neural network. 


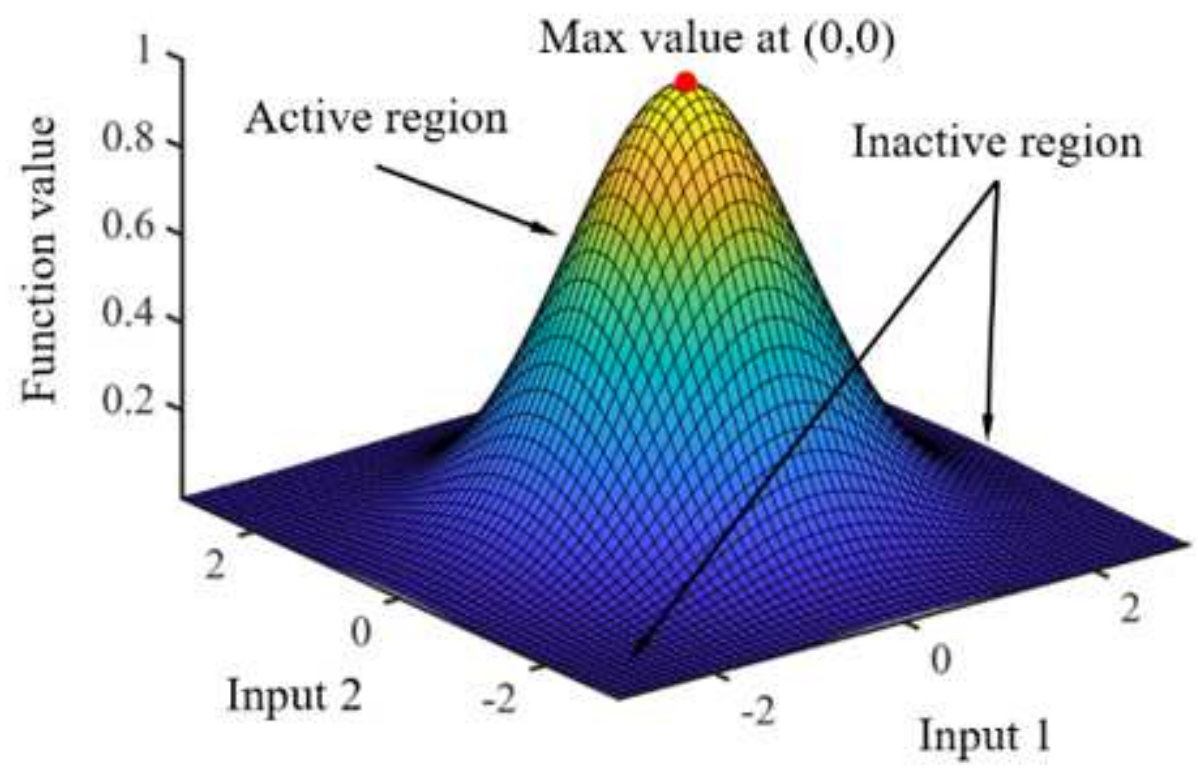

Figure 11

Amplitude-frequency response curves for different crack position at node $10(\lambda=0.5)$
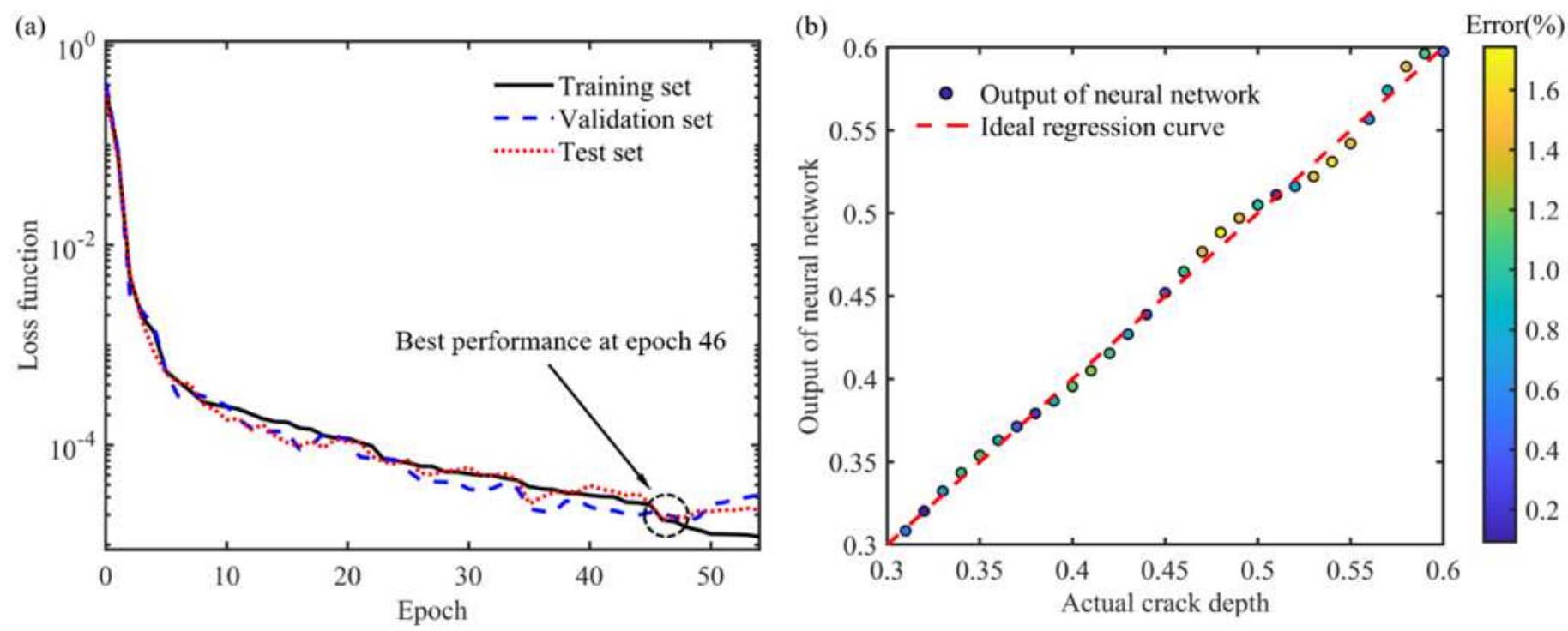

Figure 12

Training and test results of the RBF network when the crack is located in the middle of the rotor system: (a) Loss function curve. (b) Regression output. 

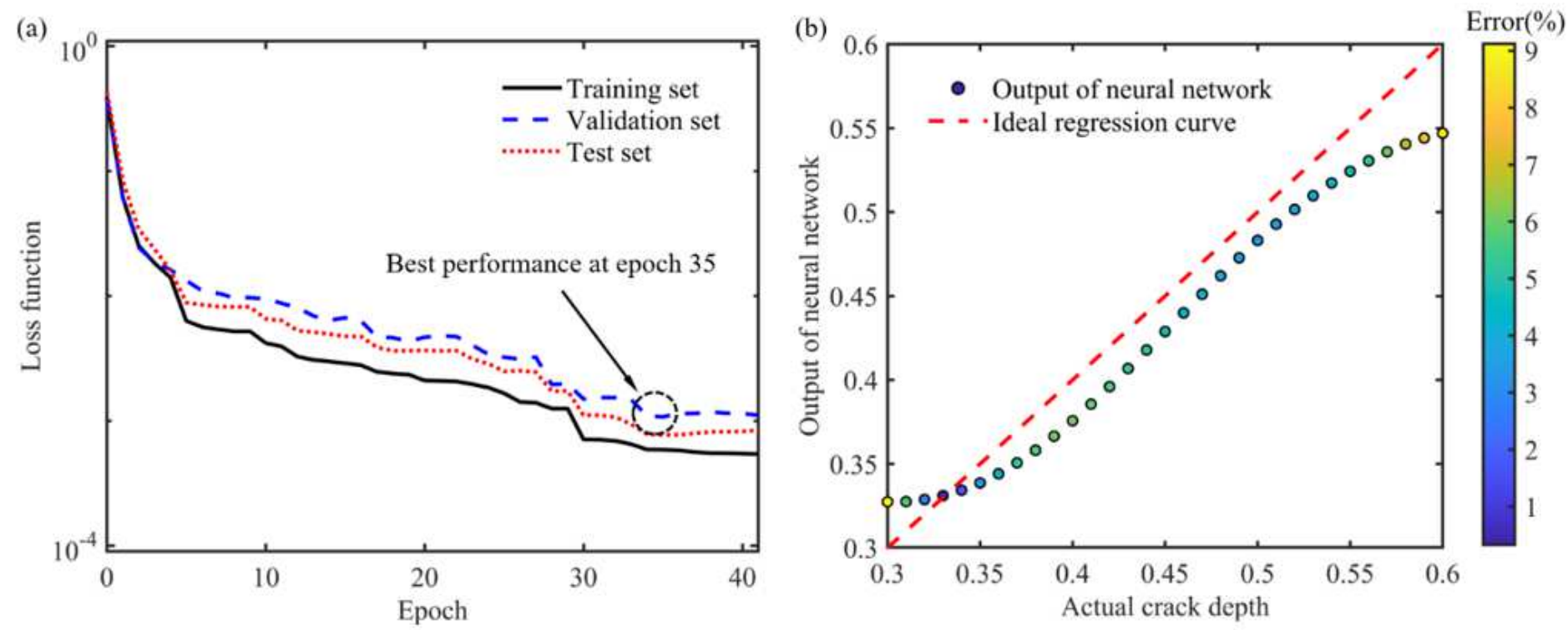

\section{Figure 13}

Training and test results of the RBF network when the crack is located at the end of the rotor system: (a) Loss function curve. (b) Regression output.
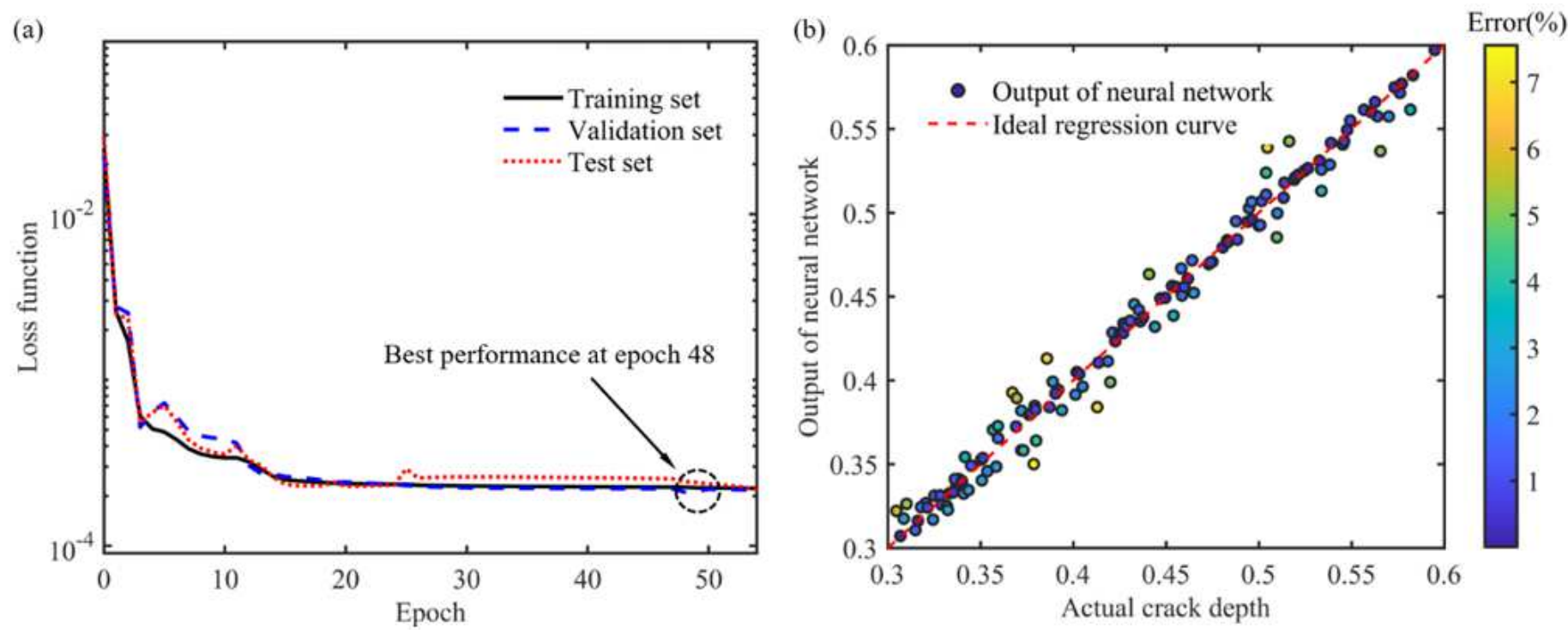

Figure 14

Training and test results of the RBF network when the crack position is uncertain: (a) Loss function curve. (b) Regression output. 


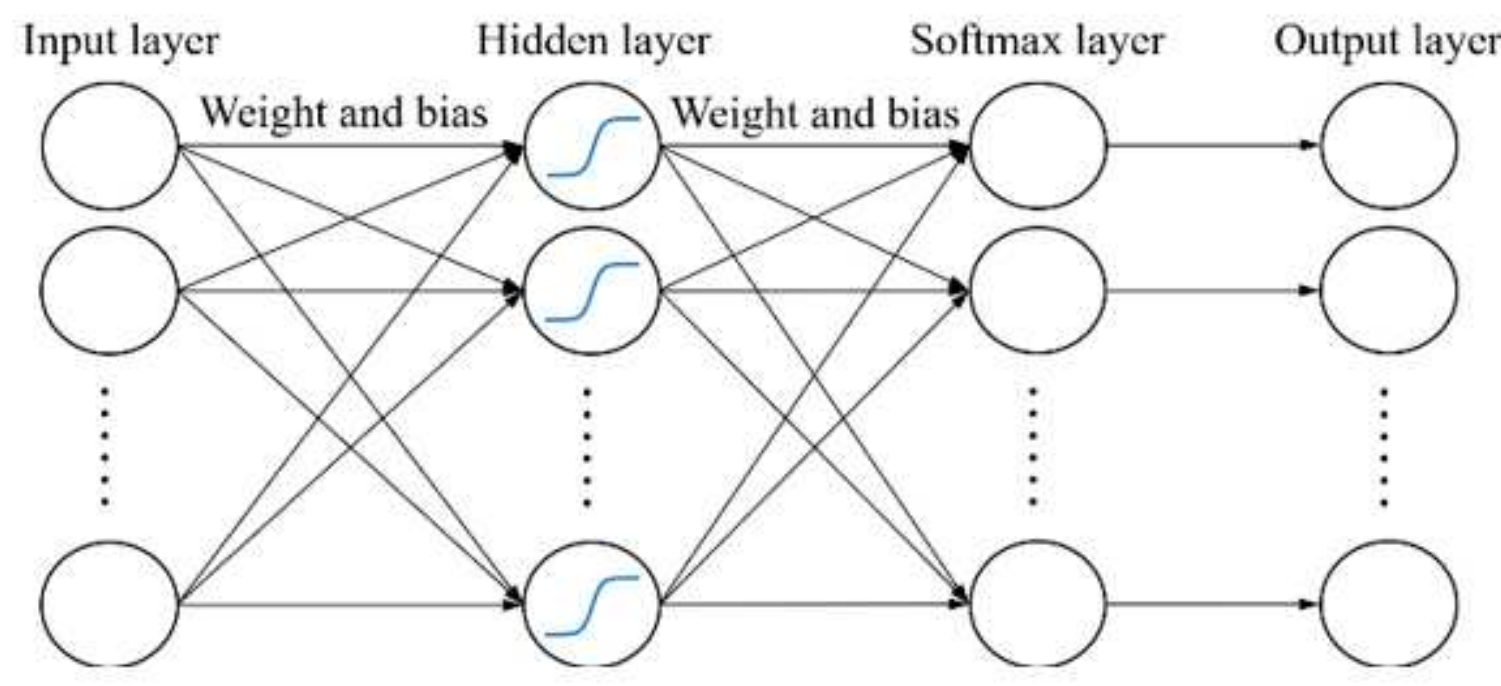

Figure 15

The structure of the pattern recognition network

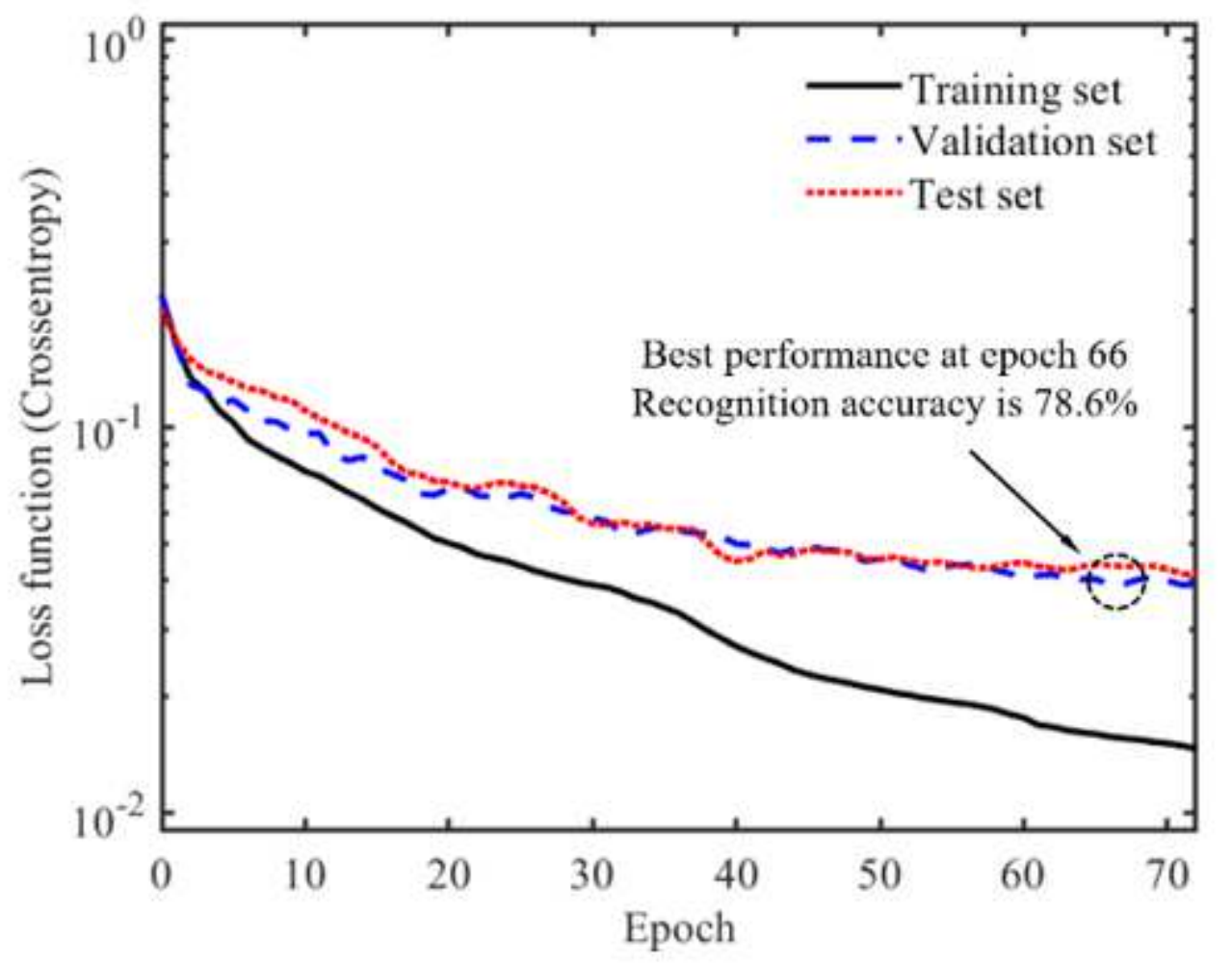

Figure 16

The loss function curve of PRNN in the training process 


\begin{tabular}{|c|c|c|c|c|c|c|c|c|c|c|c|c|}
\hline & & & mplete & accurate & & Approxir & ately acc & rate & Erro & & & \\
\hline 9 & $\begin{array}{c}4 \\
7.1 \%\end{array}$ & $\begin{array}{c}0 \\
0.0 \%\end{array}$ & $\begin{array}{c}0 \\
0.0 \%\end{array}$ & $\begin{array}{c}0 \\
0.0 \%\end{array}$ & $\begin{array}{c}0 \\
0.0 \%\end{array}$ & $\begin{array}{c}0 \\
0.0 \%\end{array}$ & $\begin{array}{c}0 \\
0.0 \%\end{array}$ & $\begin{array}{c}0 \\
0.0 \%\end{array}$ & $\begin{array}{c}0 \\
0.0 \%\end{array}$ & $\begin{array}{c}0 \\
0.0 \%\end{array}$ & $\begin{array}{c}0 \\
0.0 \%\end{array}$ & \\
\hline 10 & $\begin{array}{c}2 \\
3.6 \%\end{array}$ & $\begin{array}{c}3 \\
5.4 \%\end{array}$ & $\begin{array}{c}0 \\
0.0 \%\end{array}$ & $\begin{array}{c}0 \\
0.0 \%\end{array}$ & $\begin{array}{c}0 \\
0.0 \%\end{array}$ & $\begin{array}{c}0 \\
0.0 \%\end{array}$ & $\begin{array}{c}0 \\
0.0 \%\end{array}$ & $\begin{array}{c}0 \\
0.0 \%\end{array}$ & $\begin{array}{c}0 \\
0.0 \%\end{array}$ & $\begin{array}{c}0 \\
0.0 \%\end{array}$ & $\begin{array}{c}0 \\
0.0 \%\end{array}$ & \\
\hline 11 & $\begin{array}{c}0 \\
0.0 \%\end{array}$ & $\begin{array}{c}0 \\
0.0 \%\end{array}$ & $\begin{array}{c}4 \\
7.1 \%\end{array}$ & $\begin{array}{c}0 \\
0.0 \%\end{array}$ & $\begin{array}{c}0 \\
0.0 \%\end{array}$ & $\begin{array}{c}0 \\
0.0 \%\end{array}$ & $\begin{array}{c}0 \\
0.0 \%\end{array}$ & $\begin{array}{c}0 \\
0.0 \%\end{array}$ & $\begin{array}{c}0 \\
0.0 \%\end{array}$ & $\begin{array}{c}0 \\
0.0 \%\end{array}$ & $\begin{array}{c}0 \\
0.0 \%\end{array}$ & \\
\hline 12 & $\begin{array}{c}0 \\
0.0 \%\end{array}$ & $\begin{array}{c}0 \\
0.0 \%\end{array}$ & $\begin{array}{c}0 \\
0.0 \%\end{array}$ & $\begin{array}{c}1 \\
1.8 \%\end{array}$ & $\begin{array}{c}3 \\
5.4 \%\end{array}$ & $\begin{array}{c}0 \\
0.0 \%\end{array}$ & $\begin{array}{c}0 \\
0.0 \%\end{array}$ & $\begin{array}{c}0 \\
0.0 \%\end{array}$ & $\begin{array}{c}0 \\
0.0 \%\end{array}$ & $\begin{array}{c}0 \\
0.0 \%\end{array}$ & $\begin{array}{c}0 \\
0.0 \%\end{array}$ & \\
\hline 13 & $\begin{array}{c}0 \\
0.0 \%\end{array}$ & $\begin{array}{c}0 \\
0.0 \%\end{array}$ & $\begin{array}{c}0 \\
0.0 \%\end{array}$ & $\begin{array}{c}1 \\
1.8 \%\end{array}$ & $\begin{array}{c}1 \\
1.8 \%\end{array}$ & $\begin{array}{c}0 \\
0.0 \%\end{array}$ & $\begin{array}{c}1 \\
1.8 \%\end{array}$ & $\begin{array}{c}0 \\
0.0 \%\end{array}$ & $\begin{array}{c}0 \\
0.0 \%\end{array}$ & $\begin{array}{c}0 \\
0.0 \%\end{array}$ & $\begin{array}{c}0 \\
0.0 \%\end{array}$ & \\
\hline 14 & $\begin{array}{c}0 \\
0.0 \%\end{array}$ & $\begin{array}{c}0 \\
0.0 \%\end{array}$ & $\begin{array}{c}0 \\
0.0 \%\end{array}$ & $\begin{array}{c}0 \\
0.0 \%\end{array}$ & $\begin{array}{c}0 \\
0.0 \%\end{array}$ & $\begin{array}{c}4 \\
7.1 \%\end{array}$ & $\begin{array}{c}4 \\
7.1 \%\end{array}$ & $\begin{array}{c}0 \\
0.0 \%\end{array}$ & $\begin{array}{c}0 \\
0.0 \%\end{array}$ & $\begin{array}{c}0 \\
0.0 \%\end{array}$ & $\begin{array}{c}0 \\
0.0 \%\end{array}$ & \\
\hline 15 & $\begin{array}{c}0 \\
0.0 \%\end{array}$ & $\begin{array}{c}0 \\
0.0 \%\end{array}$ & $\begin{array}{c}0 \\
0.0 \%\end{array}$ & $\begin{array}{c}0 \\
0.0 \%\end{array}$ & $\begin{array}{c}0 \\
0.0 \%\end{array}$ & $\begin{array}{c}0 \\
0.0 \%\end{array}$ & $\begin{array}{c}0 \\
0.0 \%\end{array}$ & $\begin{array}{c}0 \\
0.0 \%\end{array}$ & $\begin{array}{c}0 \\
0.0 \%\end{array}$ & $\begin{array}{c}0 \\
0.0 \%\end{array}$ & $\begin{array}{c}0 \\
0.0 \%\end{array}$ & \\
\hline 17 & $\begin{array}{c}0 \\
0.0 \%\end{array}$ & $\begin{array}{c}0 \\
0.0 \%\end{array}$ & $\begin{array}{c}0 \\
0.0 \%\end{array}$ & $\begin{array}{c}0 \\
0.0 \%\end{array}$ & $\begin{array}{c}0 \\
0.0 \%\end{array}$ & $\begin{array}{c}0 \\
0.0 \%\end{array}$ & $\begin{array}{c}0 \\
0.0 \%\end{array}$ & $\begin{array}{c}2 \\
3.6 \%\end{array}$ & $\begin{array}{c}0 \\
0.0 \%\end{array}$ & $\begin{array}{c}0 \\
0.0 \%\end{array}$ & $\begin{array}{c}0 \\
0.0 \%\end{array}$ & \\
\hline 18 & $\begin{array}{c}0 \\
0.0 \%\end{array}$ & $\begin{array}{c}0 \\
0.0 \%\end{array}$ & $\begin{array}{c}0 \\
0.0 \%\end{array}$ & $\begin{array}{c}0 \\
0.0 \%\end{array}$ & $\begin{array}{c}0 \\
0.0 \%\end{array}$ & $\begin{array}{c}0 \\
0.0 \%\end{array}$ & $\begin{array}{c}0 \\
0.0 \%\end{array}$ & $\begin{array}{c}1 \\
1.8 \%\end{array}$ & $\begin{array}{c}1 \\
1.8 \%\end{array}$ & $\begin{array}{c}0 \\
0.0 \%\end{array}$ & $\begin{array}{c}0 \\
0.0 \%\end{array}$ & \\
\hline 19 & $\begin{array}{c}0 \\
0.0 \%\end{array}$ & $\begin{array}{c}0 \\
0.0 \%\end{array}$ & $\begin{array}{c}0 \\
0.0 \%\end{array}$ & $\begin{array}{c}0 \\
0.0 \%\end{array}$ & $\begin{array}{c}0 \\
0.0 \%\end{array}$ & $\begin{array}{c}0 \\
0.0 \%\end{array}$ & $\begin{array}{c}0 \\
0.0 \%\end{array}$ & $\begin{array}{c}0 \\
0.0 \%\end{array}$ & $\begin{array}{c}0 \\
0.0 \%\end{array}$ & $\begin{array}{c}4 \\
7.1 \%\end{array}$ & $\begin{array}{c}0 \\
0.0 \%\end{array}$ & \\
\hline 20 & $\begin{array}{c}0 \\
0.0 \%\end{array}$ & $\begin{array}{c}0 \\
0.0 \%\end{array}$ & $\begin{array}{c}0 \\
0.0 \%\end{array}$ & $\begin{array}{c}0 \\
0.0 \%\end{array}$ & $\begin{array}{c}0 \\
0.0 \%\end{array}$ & $\begin{array}{c}0 \\
0.0 \%\end{array}$ & $\begin{array}{c}0 \\
0.0 \%\end{array}$ & $\begin{array}{c}0 \\
0.0 \%\end{array}$ & $\begin{array}{c}0 \\
0.0 \%\end{array}$ & $\begin{array}{c}0 \\
0.0 \%\end{array}$ & $\begin{array}{c}2 \\
3.6 \%\end{array}$ & $\begin{array}{c}\text { Total } \\
\text { accuracy }\end{array}$ \\
\hline & 9 & 10 & 11 & 12 & 13 & 14 & 15 & 17 & 18 & 19 & 20 & $\begin{array}{c}44 \\
78.6 \%\end{array}$ \\
\hline
\end{tabular}

Figure 17

The part of the confusion matrix of PRNN results with misclassification category 